\title{
The Crowded Crosstalk between Cancer Cells and Stromal Microenvironment in Gynecological Malignancies: Biological Pathways and Therapeutic Implication
}

\author{
Rosalba De Nola ${ }^{1, *(\mathbb{D}}$, Alessio Menga ${ }^{2}{ }^{-}$, Alessandra Castegna ${ }^{2}$, Vera Loizzi ${ }^{3}{ }^{(}$, \\ Girolamo Ranieri ${ }^{4, *}$ D, Ettore Cicinelli ${ }^{3}$ and Gennaro Cormio ${ }^{3,5}$ \\ 1 Department of Tissues and Organs Transplantation and Cellular Therapies, D.E.O.T., \\ University of Bari “Aldo Moro", Piazza G. Cesare, 11-Policlinico 70124 Bari, Italy \\ 2 Department of Biosciences, Biotechnologies and Biopharmaceutics, University of Bari "Aldo Moro", \\ Via E. Orabona, 4, 70125 Bari, Italy; mengaalessio@gmail.com (A.M.); alessandra.castegna@uniba.it (A.C.) \\ 3 Department of Biomedical and Human Oncological Science, 2nd Unit of Obstetrics and Gynecology, \\ University of Bari "Aldo Moro", Piazza G. Cesare, 11-Policlinico 70124 Bari, Italy; vera.loizzi@uniba.it (V.L.); \\ ettore.cicinelli@uniba.it (E.C.); gennaro.cormio@uniba.it (G.C.) \\ 4 Interventional Oncology Unit with Integrate Section of Translational Medical Oncology, IRCCS, \\ Istituto Tumori Giovanni Paolo II, 70124 Bari, Italy \\ 5 Gynaecologic Oncology Unit, IRCCS, Istituto Tumori Giovanni Paolo II, 70142 Bari, Italy \\ * Correspondence: rosalba.denola@virgilio.it (R.D.N.); giroran@tiscali.it (G.R.); Tel.: +39-0805555561 (G.R.)
}

Received: 17 April 2019; Accepted: 13 May 2019; Published: 15 May 2019

\begin{abstract}
The tumor microenvironment plays a pillar role in the progression and the distance dissemination of cancer cells in the main malignancies affecting women-epithelial ovarian cancer, endometrial cancer and cervical cancer. Their milieu acquires specific properties thanks to intense crosstalk between stromal and cancer cells, leading to a vicious circle. Fibroblasts, pericytes, lymphocytes and tumor associated-macrophages orchestrate most of the biological pathways. In epithelial ovarian cancer, high rates of activated pericytes determine a poorer prognosis, defining a common signature promoting ovarian cancer proliferation, local invasion and distant spread. Mesenchymal cells also release chemokines and cytokines under hormonal influence, such as estrogens that drive most of the endometrial cancers. Interestingly, the architecture of the cervical cancer milieu is shaped by the synergy of high-risk Human Papilloma Virus oncoproteins and the activity of stromal estrogen receptor $\alpha$. Lymphocytes represent a shield against cancer cells but some cell subpopulation could lead to immunosuppression, tumor growth and dissemination. Cytotoxic tumor infiltrating lymphocytes can be eluded by over-adapted cancer cells in a scenario of immune-tolerance driven by T-regulatory cells. Therefore, the tumor microenvironment has a high translational potential offering many targets for biological and immunological therapies.
\end{abstract}

Keywords: pericytes; fibroblasts; tumor-associated macrophages; lymphocytes; estrogens; Human Papilloma Virus; ovarian cancer; endometrial cancer; cervical cancer

\section{Introduction}

The tumor microenvironment plays a pillar role in the invasion, progression and subsequent dissemination of cancer cells. Considering the most common gynecological malignancies, the pathogenic process of these neoplasms includes intense crosstalk between the stromal and the cancer cells leading to the acquirement of specific pathological properties. 
In Epithelial Ovarian Cancer (EOC) malignant cells are associated with many other different ancillary cells that are present within the reactive stroma-namely pericytes, adipocytes, endothelial cells, fibroblasts and myofibroblasts, bone-marrow-derived mesenchymal stem cells (BM-MSCs), mesothelial cells and leucocytes [1-3]. The genetic expression cluster of reactive stromal signature, described by the Australian Ovarian Cancer Study Group (AOCS), predicts a poorer prognosis and correlates with high levels of desmoplasia and Alpha Smooth Muscle Actin ( $\alpha \mathrm{SMA}$ ) expression by tumor-associated myofibroblasts and pericytes $[3,4]$. This genetic signature reflects the presence of activated myofibroblasts, vascular endothelial cells, pericytes and the expression of proteins belonging to the extracellular matrix (ECM) reassessment, the cell crosstalk, cell-to-cell adhesion and neo-angiogenesis [4]. On the contrary, an immune signature defines a genetic profile of ovarian cancers with a high rate of infiltrating lymphocytes within tumoral islets that leads to a better outcome [4]. Moreover, the peritoneal cavity that is considered the typical habitat for ovarian cancer lesions, during the development of EOC, is reached by a fluid considered a "dynamic stroma" in which many different soluble factors are present. This fluid milieu is empowered by a complex "secretome," thanks to biological pathways and epigenetic processes [1].

Considering the endometrium, the stromal population around the endometrial glands is characterized by a critical juxtacrine and paracrine activity of estrogen receptor $\alpha(E R \alpha)$, encoded by the gene ESR1, which mediates the release of various growth-factors and cell-cycle-related proteins. This hormonal influence can be enhanced by the dysregulation of other pathways such as E-cadherin loss and mutations of $\beta$-catenin, also orchestrating in some cases an epithelial-mesenchymal transition (EMT) during carcinogenesis [5-7].

On the other hand, the opposite transition, that is, from mesenchymal to epithelium, has been demonstrated in an animal model of cervical cancer; both Human Papilloma Virus (HPV) and estrogenic significantly influence the stromal cells that are enriched with the paracrine release of pro-inflammatory, mitogenic and antiapoptotic factors [8,9]. Moreover, the fibroblasts surrounding HPV-infected cervical cell can be instructed to produce chemokine, C-C motif, ligand (CCL) 20 to chemoattract T-helper 17 (Th17) lymphocytes [10].

The present review will outline its involvement in the most frequent malignancies affecting women worldwide: epithelial ovarian cancer, endometrial cancer and cervical cancer. This evidence might lead by the near future to the application of target therapies and immunological treatments that will focus on the peculiar biological signature characterizing not only the cancer cells but also their vital microenvironment.

\section{Epithelial Ovarian Cancer}

EOC is the deadliest cancer of the genital tract, characterized by a significant relapse rate and poor overall survival (OS), mainly because of the usual high stage at diagnosis, which often requires a demanding surgery and the necessity of adjuvant chemotherapies [2,11].

The malignant cells are supplied by a peculiar microenvironment along and through the peritoneal lining, washed by the fluid flow into the abdominal cavity: this physio-pathological feature facilitates the seeding of secondary invasive lesions from the ovarian site without any anatomical barrier [1]. The EOC's stroma is so crucial for progression and metastatic spread of tumor cells that recent studies have identified many markers for the different tumor-related cells that are able to predict the prognosis $[2,3,11]$. The various subpopulations of cells and the molecules of the ECM in the EOC milieu contribute significantly to the accomplishment of the cancer dissemination capabilities, as it has been described by Hanahan and Weinberg [12].

Therefore, it seems important to consider not only the histological subtype but also the heterogenicity of the cancer microenvironment in the aim of better diagnosis and consequently more efficient therapy. 


\subsection{Alpha Smooth Muscle Actin ( $\alpha$-SMA) and Platelet Derived Growth Factor Beta Receptor (PDGF $\beta R$ ) Related Stroma}

\subsubsection{Tumor Growth and Metastasis Induction}

High levels of desmoplasia and Alpha Smooth Muscle Actin ( $\alpha \mathrm{SMA}$ ) expression, typical of tumor-associated myofibroblasts and pericytes, characterize the reactive stromal genotype of EOC, described by AOCS [3,4]. This genetic signature determines the deposit of a great number of collagen fibers and activated myofibroblasts (desmoplasia) but also the recruitment of vascular endothelial cell and pericytes. Moreover, the activated stroma profile depends on the expression of proteins belonging to the extracellular matrix reassessment, the cell crosstalk, cell-to-cell adhesion and neo-angiogenesis [4]. Among the EOC stroma, Cancer-Associated Fibroblasts (CAFs) are diffusely present and they take origin from different cell lines. Therefore, CAFs can exhibit different markers depending on the derivation from local fibroblast stem cells, bone marrow-derived progenitors or even epithelial components [13]. Consequently, the heterogeneous family of CAFs can be characterized by $\alpha$-SMA, Platelet Derived Growth Factor Beta Receptor (PDGF $\beta R$ ), podoplanin or FAP (Fibroblast Activation Protein). Various biological signatures could represent peculiar functions and characteristics that enable CAFs to help cancer cells in migrating from primary sites and invading new tissues [2,13]. Notably, some surveys, including the AOCS, revealed the presence of around 150 genetic common markers typical for CAFs or BM-MSCs and normal pericytes, such as PDGF $\beta R, \alpha-S M A$, regulator of G-protein signaling 5, caldesmon 1, Melanoma Cell Adhesion Molecule/Cluster of Differentiation 146 (MCAM/CD146), Cluster of Differentiation (CD) 73, angiopoietin 1, Fibroblast Growth Factor (FGF), Fibroblast Growth Factor Receptor (FGFR) and Notch associated molecules [3]. In details, it has been described that normal pericytes usually have decreased levels of $\alpha$-SMA, so they form a contractile layer enveloping the endothelium of capillaries and venules. The recruitment of pericytes in the tumor growth and subsequent dissemination, depend on both PDGF $\beta R$ and its endothelial-derived ligand (PDGF $\beta$ ) and so it can be detected by the new expression of $\alpha$-SMA. Furthermore, it is known that inhibiting the pathway of PDGF $\beta R$ in the CAFs population slows the tumor growth [2]. CAFs can be activated by the presence of TGF- $\beta$ that induces the over-expression of the versican gene (VCAN) upregulating, in turn, the transcription factor NF- $\mathrm{KB}$ [14]. The consequent molecular cascade promotes the enhancement of EOC cells' motility leading to higher chances of overgrowth and invasion [14]. However, a recent in vivo study performed on nude mice in which metastatic serous ovarian cancer (OVAR-5) were injected subcutaneously before chemotherapy, demonstrated the key role of pericytes more than CAFs in bursting the tumor burden and promoting aggressive outgrowth. There were three groups under study: OVAR- 5 alone; OVAR- 5 with pericytes, OVAR- 5 with fibroblasts. The last two groups of animals displayed a tumoral/stromal cells ratio of 10:1 [3]. Strikingly, in the second group, tumoral growth and load increased significantly in a directly proportional way at the rising of pericytes rate. Additionally, also the local invasiveness of the second group arose, leading to an invasive growth beyond the boundaries of the initial tumor mass that was visible to the naked eye [3]. Interestingly, the same study analyzed that the speed and the distance of metastatic seeding of OVCAR- 5 cells increased following a direct correlation with the pericytes rate, whereas the controls invaded only the nearest sites to the primary the lesion, for example, bowel and peritoneum. Even though the pericytes rate is directly related to tumor growth and distant dissemination, it has been demonstrated that pericytes can attract other stromal $\alpha-\mathrm{SMA}^{+}$cells without an actual proliferation, tested with the immunohistochemical assessment of the cell-proliferation antigen Ki67 [3,15]. Notably, the pericytes promoted invasion and metastatic dissemination also in a non-metastatic ovarian cancer model (OVCAR-8) [3]. In the end, we could state that activated pericytes and CAFs share a common signature promoting ovarian cancer proliferation, local invasion and distant spread but the former ones behave more powerfully and efficiently. 


\subsubsection{Pericytes Draw the Architecture of Further Functional Vessels}

Both CAFs and pericytes are involved in neo-angiogenesis of EOC, even though the leading role in this process is held by leukocytes. CAFs are responsible for the release of many pro-angiogenic molecules, such as VEGF-A (vascular endothelial growth factor-A) induced by the action of prostaglandin E2 and bradykinin B2. Moreover, the expression of FGF type 2, also known as basic FGF [16], is promoted by the stimulation of CAFs mediated by PDGF or chemokine C-X-C motif ligand (CXCL) [14]. In a breast cancer model, CAFs induce the chemoattraction of the endothelial cells precursors: their structure and function are shaped on the guise of pilot sheets of $\alpha \mathrm{SMA}^{+}$pericytes recruited in the cancer stroma by the PDGF $\beta$ signaling [12,17]. In detail, endothelial cells build new blood vessels in the path of the pericytes' scaffold under the effect of a pro-angiogenic scenario within the TME, orchestrated by a huge variety of classical pro-angiogenic factors such as VEGF, FGF-2, PDGF, angiotensin, Insulin-like Growth Factor (IGF), Tumor Necrosis Factor (TNF), IL-6 and non-classical ones (i.e., tryptase and chymase) [18]. Consequently, both endothelial cells and pericytes undergo the up-regulation of many biological cascades involved in angiogenesis, tumor growth, local invasion and metastasis, as follows MAPK, phospholipase C $\gamma$ (PLC $\gamma$ ), Src, Janus kinase (JAK)/Signal Transducer and Activator of Transcription (STAT) and phosphoinositide 3 kinase (PI3K) [18].

Recently, an in vivo study evaluated two models of the angiogenic process in the peritoneal EOC islands using two intraperitoneally growing cell lines grafts in mouse, named IGROV-1 (human high grade serous ovarian carcinoma xenografts) and the ID8 syngeneic mouse ovarian cancer model both labeled by the expression of a lentivirus, eGFP [17]. Researchers observed that after 3 weeks IGROV-1 peritoneal seeds started to show an initial vascularization within the mesenteric spaces reaching definitive and complete viable blood vessels by 6 weeks in all tumor islands sized more the $100 \mu \mathrm{m}$. The same experiment was applied to the ID8 model, showing the presence of the first blood vessel between 4 and 10 weeks after the cancer cell intraperitoneal injection. Furthermore, subsequent steps of neo-angiogenesis were studied through confocal microscopy with the help of specific staining for functional blood vessels, $\mathrm{CAFs}$ and $\alpha-\mathrm{SMA}^{+}$pericytes knowing that EOC cells grafts were positive for eGFP. They observed that $\alpha$-SMA ${ }^{+}$pericytes' layers were identifiable since the early phase of neo-angiogenesis of avascular peritoneal deposits, but they remained stable as a sort of basements for the future vessels' walls created by the endothelium [17]. However, Sinha et al. showed that the pericyte coverage index of $\mathrm{CD} 34^{+}$blood vessels was the same between controls and graft tissues co-injected with pericytes [3]. Thus, the recruitment of $\alpha$-SMA ${ }^{+}$cells to the Tumor Micro-Environment (TME) of EOC graft model does not affect the possibility for the malignant cells to chemoattract and activate other mesenchymal cells for blood supply. Notably, the eradication of the pericytes population from the TME might determine a wide range of destabilizing effects because of a partial decrease in tumor vasculature as it happens during the treatment with AX102 (an inhibitor of PDGF- $\beta$ signaling) or in mice holding a mutation in the PDGF- $\beta$ retention, causing a mild reduction in the number of pericytes [3].

\subsubsection{Poor Prognosis and Translational Relevance}

The first clinical evidence of molecular alterations of TME was given by Corvigno et al., who demonstrated that high PDGF $\beta R^{+}$stroma fraction correlates with a poorer outcome even after a statistical adjustment for clinical prognostic features [2]. This marker characterizes CAFs but also pericytes, even though the latter ones are better identified by $\alpha$ SMA when associated with tumors [2].

Experimental studies have demonstrated that the PDGF $\beta$ R pathway is involved in the recruitment and activation of CAFs, leading to tumor growth, dissemination and chemoresistance. Therefore, the inhibition of the PDGRF $\beta$ signaling may be critical to overcome some of these features and assess new target therapies against TME elements [2]. However, Sinha et al. demonstrated that pericyte-score, a pericyte-specific gene signature identified by AOCS, correlates with $\alpha \mathrm{SMA}^{+}$cells' rate. Furthermore, this pericyte-score behaves as a strong predictor for early relapse and increased mortality with reduction of progression-free survival (PFS) and overall survival (OS) [3]. In particular, the mean PFS rockets 
from 9 to 29 months in case of low pericytes score. Moreover, in the early relapsed group there is higher gene expression, enhanced by pericytes, that promotes cell proliferation, migration, cell motility and reduces cell-to-cell adhesion without affecting significantly angiogenesis in EOC [3].

The pillar role of pericytes could be hidden by the presence of many co-expressed markers in common with CAFs and BM-MSCs, such as $\alpha$ SMA, MCAM/CD146 and CD73. Moreover, Sinha et al. showed that even a small number of pericytes co-injected with the tumor graft in mice can influence the TME and consequently the EOC behavior thanks to the recruitment of host $\alpha \mathrm{SMA}^{+}$stromal and Stem Cell Antigen $1^{+} / \mathrm{CD}^{+} 3^{+} \mathrm{BM}-\mathrm{MSC}$ [ [3]. These mesenchymal cells within the TME predict poor prognosis and metastasis, even in the case of OVCAR-8 graft [3].

A future goal for translational research could be the identification of all the signaling molecules released by pericytes to induce tumor growth, dissemination and early relapse. Thence, these proteins may be used as next targets for biological therapies in the EOC scenario.

\subsection{Leucocytes}

2.2.1. Imbalance of the Lymphocytes' Subtypes Correlates with immunosuppressive Environment and Angiogenesis

Lymphocytes represent the shield against cancer cells but some cell subpopulations could hold negative effects on tumors' pathophysiology, leading to immunosuppression, tumor growth and dissemination. In the EOC milieu, we can distinguish a variety of immune cells, which create a complex network in the peritumoral stroma, mainly between the epithelial cells. $T$ cells, identified by the constitutive subunit $\mathrm{CD}^{+}$, represent the main percentage of all $\mathrm{CD}_{4} 5^{+}$cells within tumoral islets, varying from 35 to $55 \%$ in EOC [19]. Once away from the bloodstream, natural killer (NK) cells, T-cells, B-cells, mast cells and macrophages migrate into the peritumoral stroma and EOC islets, within the space between epithelial cells [20].

TILs, an abbreviation that indicates tumor-infiltrating lymphocytes, are involved in the remodeling process because they can mediate immune editing of cancer cells in three main steps: elimination, equilibrium and escape. Firstly, TILs that belong to both innate and adaptive immune system chase after tumoral cells and fight against them to inhibit the building of cancer mass. Next, the remnant EOC cells survive in peculiar homeostasis with their "hunters" because of two main reasons: a variety of stronger phenotypes acquired by tumoral cells and a different microenvironment of adaptive immune cells, balanced mainly by cytotoxic $\mathrm{CD} 8^{+}$lymphocytes and $\mathrm{CD} 4^{+} \mathrm{CD} 25^{+} \mathrm{T}$-regulatory cells $\left(\mathrm{T}_{\text {regs }}\right)$, responsible for antigen self-tolerance. Finally, cancer cells become skilled at immune camouflage, realizing one of the most powerful tumor hallmarks that consist of escaping from antigen recognition and killing [12,13]. At this point, the tumoral mass becomes clinically relevant [21,22]. It can be concluded that inflammatory cells, mostly the cytotoxic ones, play a pivotal role in the tumor growth restriction but they can be eluded and partly defeated by over-adapted cancer cells and the consequent stroma remodeling.

The benefits of TILs presence within EOC is mainly pronounced for $\mathrm{CD} 8^{+}$lymphocytes especially when they co-express the integrin $\alpha_{\mathrm{E}}(\mathrm{CD} 103) / \beta_{7}$. This is a typical marker of intraepithelial lymphocytes of regular skin and intestinal mucosa, even though the bloodstream lacks of $\mathrm{CD} 103^{+} \mathrm{T}$ cells (since they account just for $2 \%$ ). Notably, CD103 acts only as a receptor for E-cadherin covering epithelial cells' outer membrane. Consequently, its axis anchors $\mathrm{T}$ cells to healthy and tumoral epithelium causing a forced homing of immune cells, specific for local tissue antigens.

EOCs stands for a variety of different malignancies with different biology and behavior even deeply in their microenvironment: the highest mean rate of $\mathrm{CD}_{103^{+}}$has been found in serous histological subtype, then endometrioid followed by clear cell and mucinous [23]. However, the positive prognostic value of $\mathrm{CD}^{+} \mathrm{CD} 13^{+}$, evaluated as the percentage of Specific Disease survival, was statistically significant only in High Serous Grade Carcinoma (HSGC), followed by mucinous [23]. Despite this, the pivotal role of $\mathrm{CD}_{103}{ }^{+} \mathrm{CD}^{+} \mathrm{T}$ cells and $\mathrm{CD}_{103}{ }^{+} \mathrm{NK}$ cells in juggling the intraepithelial immune response and managing tumor overgrowth emerged strongly in HGSC. In other words, CD103 acts as 
a marker for "tissue-resident memory" on the surface of $\mathrm{CD} 8^{+} \mathrm{T}$ cells $\left(\mathrm{CD} 8^{+} \mathrm{TRM}\right)$ and determines a good prognosis for patients with EOC [23]. Among cytotoxic lymphocytes, CD8 ${ }^{+} \mathrm{T}$ cells need the action of helper cells and the Human Leucocyte Antigen (HLA) system, whereas NK lymphocytes become active after the direct contact with cancer cells. In the last years, different studies produced numerous evidence about different lymphocytes' subpopulations. Firstly, it has been demonstrated that Class I HLA expression correlates with the density of $\mathrm{CD} 8^{+} \mathrm{TILs}$ and induces their activation and proliferation in the presence of interleukin (IL) 15 and 17 [20]. Moreover, islets of tumor rich of $\mathrm{CD}^{+} / \mathrm{CD}^{+}$TILs show a high mRNA level of interferon $\gamma$ (INF $\gamma$ ) and IL-2, secreted by $\mathrm{CD} 4^{+}$ T-helper 1 cells and activated CD8 ${ }^{+} \mathrm{T}$ cells $[19,24]$. Furthermore, TEM with TILs is also positive for macrophage-derived chemokines and secondary lymphoid-tissue chemokine proteins. Therefore, there is a strong positive correlation between the number of $\mathrm{CD}^{+}$and $\mathrm{CD}^{+}$among TILs in EOC ( $p$-value $<0.001)$. On the contrary, these chemokines were undetectable as mRNA in case of EOCs without T-cells infiltration $[19,24]$.

In details, the function of INF $\gamma$ is critical in the EOC microenvironment, even in the ascites and peritoneal dissemination seeds, showing a positive correlation with the CD8 ${ }^{+} \mathrm{TILs}^{\prime}$ concentration. However, higher levels of INF $\gamma$ induce the expression of PD- Ligand 1 (PD-L1) on ovarian cancer cells and inhibit $\mathrm{CD} 8^{+} \mathrm{T}$ cells via $\mathrm{PD}-1$, the relative matching receptor. Once the effector $\mathrm{T}$ cells are blocked by PD-1/PD-L1 axis, they cannot sustain the cell cycle steps and consequently, they undergo apoptosis $[19,24]$. A similar negative function belongs to Cytotoxic T-Lymphocyte-Associated Protein 4 (CTL4) because of the check-point blockade in effector T cells [20].

Activated cytotoxic $\mathrm{CD} 8^{+}$lymphocytes share their tumoral islet spaces also with oligoclonal $\mathrm{CD} 20^{+}$ $B$ lymphocytes, which have already experienced antigen recognition and subsequent class-switching for Ig-G [25]. Interestingly, their antibodies differ from the serum ones that recognize usual cancer antigens, such as TP53 or NY-ESO-1. Since CD20+ TILs have no impact on the humoral response, they might join the cellular immunity helping the $\mathrm{CD}^{+}$subset. Nielsen et al. (2012) found that $\mathrm{CD} 20^{+}$ cells, which occupy intraepithelial spaces and peritumoral stroma, colocalize with $\mathrm{CD}^{+}$in EOC, improving survival at a higher rate than $\mathrm{CD}^{+}$alone. Moreover, $\mathrm{CD} 20^{+}$TILs are positive for typical Antigen-Presenting-Cells (APCs), such as MHC Class I and II, CD80, CD86, and CD40. An intriguing hypothesis explaining this finding is that B cells may prevent cytotoxic cells' anergy, playing the role of a stimulation reservoir for a persistent tumor lysis activity [25].

The immune response against EOC is balanced by the inhibiting function of $T_{\text {regs, }}$, which is characterized by the expression of the forkhead box P3 (FOXP3) and two peculiar clusters of differentiation, namely CD4 and CD25. It is well known that $\mathrm{T}_{\text {regs }}$ alter the EOC milieu restraining the ability of the immune system to destroy cancer cells through the release of inhibitory cytokines, mostly Tumor Grow Factor $\beta$ (TGF- $\beta$ ) and IL-10, and/or thanks to a direct cell-to-cell block [20]. A population of regulatory cells is fundamental under a regular situation but in an oncological setting it reduces the chances to survive because of an undesirable "self-tolerance." The activation trigger for $\mathrm{T}_{\text {regs }}$ is represented by the presence of CCL28 that arises under hypoxia condition, in such a way that the tumor overgrowth settles a vicious cycle [20]. The population of $T_{\text {regs }}$ increases in case of TILs enriched with $\mathrm{B} 7 \mathrm{H} 4^{+}$tumor-associated macrophages (TAMs) contributing to reducing the outcome. Other negative actors in the immune microenvironment of EOC are represented by up-regulated vascular endothelial growth factor (VEGF), a pro-angiogenic but also an immunosuppressive factor, and endothelin-B that reduces the permeability of tumoral blood vessels, the lymphocytes diapedesis and, as a consequence, their possibility to contrast the cancer cells [20]. TME can be turned into a pro-angiogenic set by the interplay between cancer cells and stromal ones, mainly leucocytes. The main sources of pro-angiogenic factors, classical (i.e., VEGF) or non-classical ones (i.e., tryptase), are macrophages and mast cells under hypoxic conditions [18,26]. 
2.2.2. Imbalance of the Lymphocytes' Subtypes Correlates with Poor Prognosis but Harbors a Highly Critical Translational Significance

The presence of TILs represents a critical signature for the prognosis of patients with EOC, as demonstrated by many recent studies. The $\mathrm{CD}^{+}$inflammatory milieu is present in $55 \%$ of EOCs and it is responsible for a significantly higher 5-year survival (38.0\%) compared to the absence of TILs (4.5\%). Notably, the median PFS in case of T-cells populations within tumoral islets is 22.4 months and the median OS accounts for 50.3 months; on the other hand, their values plummet to 5.8 and 18 months, respectively in EOCs without T-lymphocytes ( $p$-value $<0.001$ for both comparisons) [19]. Similar results involve the subgroup of patients with complete response after optimal debulking surgery and adjuvant chemotherapy based on platinum: people with the evidence of $\mathrm{T}$ cells' presence at the pathological exam have a 5-year OS rate of 73.9\%, whereas the others without T-cell TILs have just an $11.9 \%$ OS rate [19]. However, a multivariate analysis showed that optimal debulking surgery and the presence of TILs behave as independent good prognostic factors for EOC [19].

The main role is played by $\mathrm{CD} 8^{+} \mathrm{T}$ cells, especially when they carry also CD103 as memory antigen and in case of colocalization with $\mathrm{CD} 20^{+} \mathrm{B}$ cells, leading to a survival rocketing. Even though $\mathrm{CD}^{+}$TILs can infiltrate every EOC's histological type, their prognostic benefit is more evident in HGSC $[19,23,25]$. Since VEGF reduces the number of TILs, it is associated with a poorer outcome as in case of the low rate of INF $\gamma$, IL-2, and lymphocyte-attracting chemokines. In details, the up-regulation of VEGF correlates with early recurrence (within 6 months; odds ratio $=0.34$; area under the curve $=0.80$; $p$-value $=0.05)$. On the contrary, overexpression of macrophage-derived chemokine predicts late recur [19]. Similarly, endothelin prevents T-cells from homing within tumoral islets and consequently it mines the survival possibilities. Therefore, it has been demonstrated that knock-down mouse for endothelin presented an increased population of TILs [20].

$\mathrm{CD}^{+}$lymphocytes and $\mathrm{CD} 4^{+} \mathrm{T}_{\text {regs }}$ are considered as two contrasting subpopulations of T-cells among TILs: the former ones predict a longer survival, whereas the latter ones correlate with immune suppression and poor survival in solid tumors. The ratio $\mathrm{CD}^{+} \mathrm{FOXP}_{3} \mathrm{C}^{+} \mathrm{T}_{\text {regs }} / \mathrm{CD}^{+} \mathrm{T}$ cells rises when the tumor contains also $\mathrm{B} 7 \mathrm{H} 4^{+}$TAMs, leading to decreased cancer lysis and poorer outcome. Thus, the possibility of obtaining a $\mathrm{T}_{\text {regs }}$ depletion and/or more easily converting them into $\mathrm{T}$ helper 17, in the presence of IL2, might be a therapeutic perspective [20]. Aoki et al. (1991) used IL2 in the first human adoptive TILs for the therapy of advanced or recurrent EOC: autologous CD8 ${ }^{+}$TILs taken form pleural effusion were cultured with IL2, expanded and then infused with or without chemotherapy [27]. As a result, 7 patients in 10 who received both TILs and chemotherapy had a complete response, whereas in the other group the complete response accounted just for one case among seven patients [27]. Unfortunately, this kind of immunotherapy has many pitfalls and it can fail because of the typical HLA downregulation acquired by EOC to evade the T cells recognition. Consequently, their infiltration within the tumor is reduced as the adoptive TILs therapy efficacy [20]. An interesting preclinical study on mouse EOC model showed that the contemporary inhibition of CTLA-4 and PD-1, associated with vaccination, determined the rejection of the tumor [28]. Furthermore, phase II clinical studies demonstrated encouraging results for anti-PD-1 and CTLA-4 but more studies are needed to confirm the data. Since CD137 ${ }^{+}$TILs have strong activity against tumor overgrowth, some preclinical studies introduced the use of the agonistic antibodies specific for CD137 with a positive outcome [20]. Effective immunotherapy is also the inhibition of the negative immune-modulator, precisely T-cell immunoglobulin and mucin-domain-containing-3 (TIM3), that is significantly enhanced by the combination with agonistic CD137 antibodies in murine models leading to $60 \%$ of cases free of tumor in 90 days from cancer inoculation [29]. An intriguing possibility could be the use of genetically modified $\mathrm{T}$ cells with a chimeric $\mathrm{T}$ cell receptor restricted for HLA-A2 that can bind a specific epitope of HER2, a typical EOC antigen [20].

Moreover, almost all EOC but not healthy epithelium, express Major histocompatibility complex class I-related chains (MIC) A and B and UL-16 binding proteins (ULBPs), ligands of Natural killer group 2, member D (NKG2D) that characterizes NK cells, $\mathrm{CD}^{+}$cytotoxic $\mathrm{T}$ cells and $\gamma \delta$-T cells [30]. 
Even though the stimulation of NKG2D activates the cytotoxic activities of T cells, a high expression of ULBP2 reduces the TILs number and correlates significantly with lower survival, rather than MIC A/B [30]. Notably, ULBP2 can be processed by matrix enzymes and released in the bloodstream inducing a probable central down-regulation of NKG2D expression that prevents CD8 ${ }^{+}$and $\mathrm{CD} 57^{+}$ cells from homing to tumoral islets and destroy them, as in a homeostatic system [30]. A hypothetical solution to restrain the process of TILs disruption may be a neutral competitor ligand for NKG2D or anti-ULBP2 to create an artificial balance without impairing the cytotoxic activity of $\mathrm{T}$ cells within the tumor.

\subsubsection{The Role of TAMs in EOC}

Macrophages are phagocytic cells of the innate immune system present in almost all tissues. They are a very diverse set of cells, able to significantly modify their activity in response to external stimuli. They undergo a polarization process with the expression of surface markers and the acquisition of functional states depending on the stimulating factors such as cytokines and other signals. According to the traditional concept of binary polarization, the phenotypes of activated macrophages are conventionally divided in the M1 and M2 category [31,32]. Classically activated macrophages-also known as M1 macrophages-are polarized by inflammatory signals such as IFN $\gamma$ and lipopolysaccharides (LPS), and exhibit bactericidal, immunostimulatory and antitumoral activities. By contrast, alternatively activated macrophages or M2 macrophages are polarized by anti-inflammatory signals, such as IL10, IL4, and IL13 and are involved in immunosuppression, tumor invasion, tumor growth, angiogenesis and metastasis [33-35]. Tumorigenesis is a complex phenomenon in which macrophages, also known as TAMs, play an important role as main components of the TME. During cancer progression TAMs reach a polarization state resembling that of M2 macrophages, as several M2 markers (such as CD163, CD206, PD-L1, ARG1) progressively increase [34,36], although it is becoming evident that TAMs exist in a variety of polarization states which are far from being fully elucidated [37].

In the context of the TME, many stimuli are provided by cancer cells. The EOC cells, for instance, are able to polarize macrophages toward a tumor-associated phenotype [38] by secreting several factors, such as the colony-stimulating factor 1 (CSF-1), which acts as both a chemoattractant and a mitogen for circulating monocytes via tyrosine kinase receptor CSF1-R binding [39]. It is now evident that ovarian TAMs, in response to a plethora of soluble mediators of the TME, adopt a mixed alternatively and classical phenotype, which is functionally associated to defective antitumoral functions including impaired antibody-dependent cell-mediated cytotoxicity and phagocytosis [40,41]. Genome-wide expression analysis of TAMs isolated from HGSC shows that few M2 markers such as CD163 and IL-10 are upregulated, together with the M1 markers CD86 and TNF $\alpha$, compared to non-polarized (M0) macrophages [41,42]. Evaluation of M1 (HLA-DR, iNOS) and M2-polarization (CD163, VEGF) markers in TAMs from EOC patients concluded that an increased M1/M2 ratio is associated with better overall survival $[43,44]$. In line with these findings, a higher ratio of $\mathrm{CD} 163^{+}$of $\mathrm{CD} 68^{+}(\mathrm{CD} 163 / \mathrm{CD} 68)$ TAMs and higher serum levels of CD163 correlate with higher tumor grade, worse PFS and early relapse of serous ovarian carcinoma after first-line therapy [45-49]. In addition, the expression of the alternative activation marker CD163 in TAMs strongly correlates with elevated IL6, IL10, TGF $\beta$, and polyunsaturated fatty acids (PUFAs) levels, in particular, arachidonic acid, which are signaling mediators and/or prognostic markers in ovarian cancer at different levels [41,50-55]. Similarly to CD163, the M2 marker CD206 is associated with poor prognosis in TAMs from ovarian cancer [56].

An overall view of the main TAMs functions in the EOC TME and their translational perspectives areillustrated in Figure 1.

From a functional point of view, TAMs play important functions in sustaining EOC diffusion. This is partly related to the fact that the EOC TME extents into the peritoneal fluid, which at advanced stages occur as a malignant effusion (ascites). This fluid facilitates cancer cell dissemination throughout the peritoneal cavity since it contains detached tumor cells, tumor cell spheroids, different types of innate and adaptive immune cells, as well as a plethora of tumor-promoting soluble factors and extracellular 
vehicles (EVs) [57]. Several studies have demonstrated that ovarian TAMs increase in number during cancer spread $[39,58,59]$ to the point that $50 \%$ of cells in the peritoneal TME and malignant ascites can be represented by TAMs [45], which release protumorigenic and immunosuppressive factors.

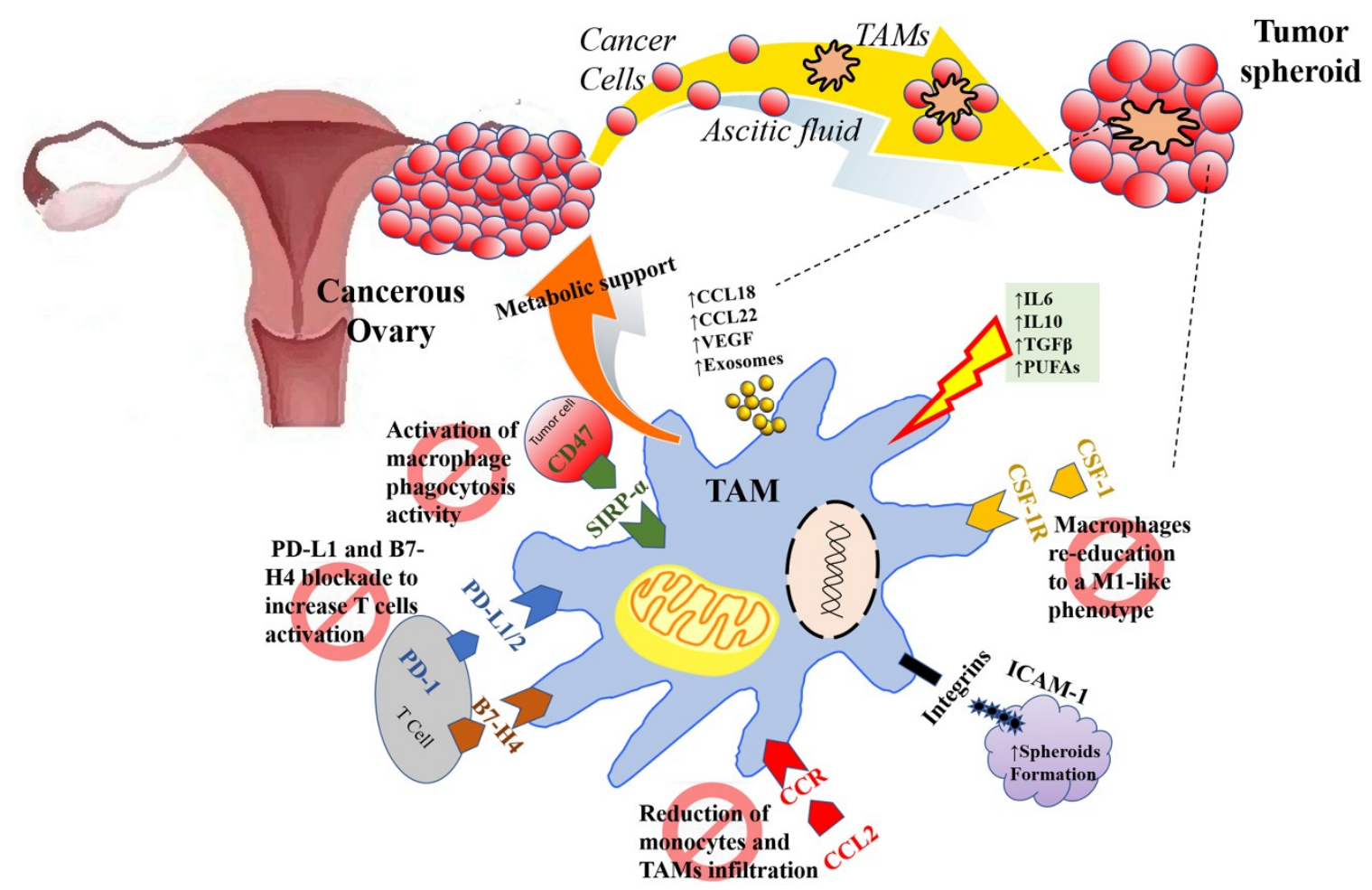

Figure 1. Tumor-associated macrophage (TAM) function in the ovarian cancer tumor microenvironment (TME) and examples of therapeutic strategies. Multiple mediators (such as IL10, IL6, TGF $\beta$, PUFAs, etc.) in the TME determine the activation state and function of TAMs. In response to these triggers, TAMs produce a plethora of tumor-promoting soluble factors (such as VEGF, CCL22, CCL18, etc.) and extracellular vehicles (Evs) and probably supply metabolic support to cancer cells. TAMs provide matrix support and growth factors also in the core of the tumor spheroids, which are stabilized by ICAM-1. During ovarian cancer progression, tumor cells detach from the primary tumor and interact with TAMs to survive in the ascitic fluid as free-floating spheroids. Blocking key macrophage pathways influences the tumorigenic and immunosuppressive activities of TAMs, providing tools for the development of novel therapies to be combined with classical chemotherapy for gynecologic cancers. Inhibiting the PD-L1/2 immune checkpoint pathway results in reactivation of T cells. Re-activation of phagocytosis and promotion of M2 to M1-like phenotype shift are achieved by inhibiting the CD47 and CSF-1R pathways, respectively. Furthermore, inhibitors of chemokines (such as CCL2) involved in the recruitment of monocytes can prevent TAMs differentiation and accumulation within the TME, thereby reducing tumor growth and dissemination.

TAMs sustain metastasis dissemination through CCL18 secretion [60] and enable the trafficking of immune-suppressive $T_{\text {regs }}$ to the ovarian tumors through CCL22 secretion [61]. Furthermore, TAMs contribute to angiogenesis by VEGF production [62] and suppress T-cell cytotoxicity by expressing both the coinhibitory molecule B7-H4 [63,64] and the PD-1 ligand PD-L1 at a higher level than EOC cells, resulting in $\mathrm{T}$ cell exhaustion and inactivation of cytotoxic $\mathrm{T}$ cell responses [65]. It has been recently demonstrated that miRNAs (miR-29a-3p and miR-21-5p) transferred from TAMs to $\mathrm{CD} 4^{+} \mathrm{T}$ cells through exosomes synergistically induce the immunosuppressive $\left(\mathrm{T}_{\text {regs }}\right) /$ proinflammatory $(\mathrm{Th17})$ T-cell imbalance, promoting an immune-suppressive microenvironment [66].

Another way by which TAMs support cancer cell dissemination is through favoring spheroid formation [67]. During EOC progression, tumor cells detach from the primary tumor and interact 
with TAMs to survive in the peritoneal fluid as free-floating spheroids. TAMs provide matrix support and growth factors in the core of the tumor spheroid in the initial steps of peritoneal carcinomatosis. TAMs secrete large amounts of EGF to activate the EGF receptor (EGFR) in surrounding tumor cells, thereby supporting tumor proliferation and anoikis protection [62]. The EGF/EGFR TAM-tumor cell crosstalk induces autocrine VEGF-C/VEGFR-3 signaling in tumor cells, which upregulates integrins and ICAM-1 necessary for maintaining cell-to-cell contact between tumor cells and TAMs (via CD11b/c) and stabilizing the tumor spheroids with (chemo)protective properties, as suggested by Freire et al. [62]. The close interaction between tumor cells and TAMs might go beyond a "physical" interaction and be characterized by a metabolic cross-talk. For example, high-invasive, aggressive and resistant ovarian cancer cells are addicted to glutamine, with high glutaminase activity and low glutamine synthesizing capacity compared to low-invasive cells [68]. The glutamine addiction of cancer cells might induce extracellular glutamine depletion, which is known to increase glutamine synthetase expression in macrophages. This metabolic feature in macrophages promotes the acquisition of an immune-suppressive, proangiogenic and premetastatic M2-like polarization state and favors macrophage-produced glutamine secretion $[69,70]$. By depleting extracellular glutamine, cancer cells might achieve a dual goal, which is the functional and metabolic TAM exploitation [71].

A summary of the main features characterizing the stromal cells within EOC's TEM and their translational relevance are described in Table 1 and in Figure 2 below.

Table 1. Main cell types of the Epithelial Ovarian Cancer's (EOC) TEM, their principal role in EOC pathogenesis and the possible translational value.

\begin{tabular}{|c|c|c|}
\hline Cell Type & Pathogenetic Role & $\begin{array}{c}\text { Translational Possibilities and } \\
\text { Hypothesis }\end{array}$ \\
\hline \multirow[t]{2}{*}{ CAFs } & $\begin{array}{c}\text { Recruited by PDGF } \beta \text { and } \\
\text { activated by TGF } \beta / \text { VCAN, CXCL. }\end{array}$ & Inhibiting PDGF- $\beta$ signaling. \\
\hline & $\begin{array}{l}\text { They promote EOC cells' motility, } \\
\text { overgrowth, neo-angiogenesis, } \\
\text { and invasion. }\end{array}$ & $\begin{array}{l}\text { Inhibiting pro-angiogenic factors } \\
\text { VEGF, FGF-2. }\end{array}$ \\
\hline \multirow[b]{2}{*}{$\alpha-\mathrm{SMA}^{+}$pericytes } & $\begin{array}{l}\text { Recruited by the PDGF } \beta \text {, their rate } \\
\text { and genetic signature correlate } \\
\text { with proliferation, migration and } \\
\text { cell motility of EOC. }\end{array}$ & \\
\hline & $\begin{array}{l}\text { They reduce cell-to-cell adhesion } \\
\text { without affecting angiogenesis } \\
\text { significantly. They build a } \\
\text { structural guide for the cancer new } \\
\text { vessels. }\end{array}$ & Inhibiting of PDGF- $\beta$ signaling. \\
\hline \multirow{3}{*}{$\mathrm{CD} 103^{+}$NK lymphocytes } & $\begin{array}{l}\text { Tumor growth restriction, innate } \\
\text { immunity. }\end{array}$ & $\begin{array}{l}\text { Neutral competitor ligand for } \\
\text { NKG2D to prevent the NK cells' }\end{array}$ \\
\hline & Activated by NKG2DLs. & anergy. \\
\hline & $\begin{array}{l}\text { High levels of circulating ULBP2 } \\
\text { (NKG2DL) fragments could } \\
\text { down-regulate the EOC' } \\
\text { expression of NKG2D }\end{array}$ & $\begin{array}{l}\text { Inhibitors of ULBP2 to prevent the } \\
\text { impairment of the NK cells' } \\
\text { cytotoxic activity }\end{array}$ \\
\hline
\end{tabular}


Table 1. Cont.

\begin{tabular}{|c|c|c|}
\hline Cell Type & Pathogenetic Role & $\begin{array}{c}\text { Translational Possibilities and } \\
\text { Hypothesis }\end{array}$ \\
\hline \multirow{4}{*}{ T helper 1 lymphocytes } & $\begin{array}{l}\text { Tumor growth restriction } \\
\text { mediated by } \mathrm{CD} 8^{+} \text {activation. }\end{array}$ & \\
\hline & $\begin{array}{c}\text { Diapedesis and differentiation } \\
\text { promoted by INF } \gamma, \text { IL-2, and } \\
\text { lymphocyte-attracting chemokines. }\end{array}$ & \\
\hline & $\begin{array}{l}\text { They secrete in turn interferon } \gamma \\
\text { (INF } \gamma \text { ) and IL-2 to chemoattract } \\
\text { cytotoxic TILs. }\end{array}$ & \\
\hline & $\begin{array}{l}\text { Diapedesis inhibited by } \\
\text { endothelin and VEGF. }\end{array}$ & $\begin{array}{l}\text { Possible chemoattraction and } \\
\text { diapedesis within TEM via } \\
\text { inhibition of endothelin and VEGF }\end{array}$ \\
\hline \multirow[t]{2}{*}{ T helper 17 lymphocytes } & $\begin{array}{l}\text { Pro-inflammatory TILs that } \\
\text { stimulate } \mathrm{CD}^{+} \text {activation. }\end{array}$ & \\
\hline & $\begin{array}{l}\text { Diapedesis inhibited by } \\
\text { endothelin and VEGF. }\end{array}$ & $\begin{array}{l}\text { Possible chemoattraction and } \\
\text { diapedesis within TEM via } \\
\text { inhibition of endothelin and VEGF. }\end{array}$ \\
\hline \multirow{5}{*}{$\begin{array}{c}\mathrm{CD}^{+} \mathrm{CD} 103^{+}\left(\mathrm{CD} 137^{+}\right) \text {cytotoxic } \\
\text { T lymphocytes }\end{array}$} & $\begin{array}{l}\text { Tumor growth restriction, } \\
\text { acquired immunity, cytotoxic } \\
\text { activity after interaction with T }\end{array}$ & $\begin{array}{c}\text { Contemporary inhibition of } \\
\text { CTLA-4 and PD-1, associated with } \\
\text { vaccination. }\end{array}$ \\
\hline & $\begin{array}{l}\text { helper. } \\
\text { Presence in serous }>\text { endometrioid } \\
>\text { clear cell }>\text { mucinous }\end{array}$ & $\begin{array}{l}\text { Agonistic antibodies specific for } \\
\text { CD137 alone or in association with } \\
\text { inhibition TIM3. }\end{array}$ \\
\hline & $\begin{array}{l}\text { histological subtype. } \\
\text { Diapedesis promoted by INF } \gamma \text {, } \\
\text { IL-2, and lymphocyte-attracting }\end{array}$ & $\begin{array}{l}\text { Autologous } \mathrm{CD}^{+} \text {TILs cultured } \\
\text { with IL2, expanded and then } \\
\text { infused. }\end{array}$ \\
\hline & chemokines. & $\begin{array}{l}\text { Chimeric T cell receptor restricted } \\
\text { for HLA-A2 that can bind a } \\
\text { specific epitope of HER2. }\end{array}$ \\
\hline & $\begin{array}{l}\text { Diapedesis inhibited by } \\
\text { endothelin and VEGF. }\end{array}$ & $\begin{array}{c}\text { Possible chemoattraction and } \\
\text { diapedesis within TEM via } \\
\text { inhibition of endothelin and VEGF. }\end{array}$ \\
\hline \multirow{4}{*}{ CD20 ${ }^{+}$B lymphocytes } & Tumor growth restriction. & \\
\hline & $\begin{array}{l}\text { They increase the survival rate of } \\
\text { CD8 }{ }^{+} \text {TILs. }\end{array}$ & \\
\hline & $\begin{array}{l}\text { CD20+ TILs might act as APCs } \\
\text { (positivity for MHC I/II, CD80, } \\
\text { CD86, and CD40) } \rightarrow \text { antigen } \\
\text { reservoir preventing CD8 }{ }^{+} \text {anergy } \\
\text { form persistent stimulation due to } \\
\text { tumor lysis activity. }\end{array}$ & \\
\hline & $\begin{array}{l}\text { Diapedesis inhibited by } \\
\text { endothelin and VEGF. }\end{array}$ & $\begin{array}{c}\text { Possible chemoattraction and } \\
\text { diapedesis within TEM via } \\
\text { inhibition of endothelin and VEGF. }\end{array}$ \\
\hline
\end{tabular}


Table 1. Cont.

\begin{tabular}{|c|c|c|}
\hline Cell Type & Pathogenetic Role & $\begin{array}{c}\text { Translational Possibilities and } \\
\text { Hypothesis }\end{array}$ \\
\hline \multirow[t]{2}{*}{$\mathrm{CD}^{+} \mathrm{CD}^{2} 5^{+} \mathrm{FOXP}^{+} \mathrm{T}_{\text {regs }}$} & $\begin{array}{c}\text { They inhibit the cytotoxic } \\
\text { functions of TILs releasing } \\
\text { inhibitory cytokines (TGF- } \beta \text { and } \\
\text { IL-10) or via a direct cell-to-cell } \\
\text { block. }\end{array}$ & $\begin{array}{c}\mathrm{T}_{\text {regs }} \text { depletion or } \\
\text { shift into T helper } 17 \text { (IL2). }\end{array}$ \\
\hline & $\begin{array}{l}\text { Activated by CCL28 under } \\
\text { hypoxia condition and in the } \\
\text { presence of } B 74^{+} \text {TAMs. }\end{array}$ & $\begin{array}{c}\text { Inhibition of CCL28; } \\
\text { immunotherapy against TAMs. }\end{array}$ \\
\hline \multirow{7}{*}{ TAMs } & CCL2/CCR recruited. & $\begin{array}{c}\text { Reducing monocytes } \\
\text { chemoattraction within TEM } \\
\text { (bisphosphonates, inhibitors CCL2 } \\
\text { antibodies). }\end{array}$ \\
\hline & $\begin{array}{l}\text { TAMs promote } \\
\text { immunosuppressive activity: } \mathrm{T}_{\text {regs }} \\
\text { trafficking to TEM (CCL22) and } \\
\text { inhibit T-cell cytotoxicity (B7-H4, } \\
\text { PD-L1). }\end{array}$ & $\begin{array}{l}\text { Inhibiting the PD-L1/2 checkpoint } \\
\text { to reactivate cytotoxic T cells. } \\
\text { Inhibition of PD-1/PD-L1 axis } \\
\text { using target antibodies } \\
\text { (pembrolizumab, nivolumab, } \\
\text { avelumab) to promote survival, } \\
\text { activation, and proliferation of } \\
\text { cytotoxic T cells. }\end{array}$ \\
\hline & $\begin{array}{l}\text { TAM offer metabolic support for } \\
\text { EOC cells (glutamine). }\end{array}$ & Depleting extracellular glutamine. \\
\hline & $\begin{array}{c}\text { Activated by IL10, IL6, TGF } \beta, \\
\text { PUFAs acquiring an M2-like } \\
\text { polarization state. }\end{array}$ & $\begin{array}{l}\text { Shifting the M2 to M1-like } \\
\text { (pro-inflammatory and } \\
\text { anti-angiogenetic) via TLR4 } \\
\text { signaling (PCX), via inhibition of } \\
\text { mTOR/p70S6K (neferine), via the } \\
\text { inhibition of inhibitors of the }\end{array}$ \\
\hline & $\begin{array}{l}\text { TAM promote angiogenesis } \\
\text { (VEGF). }\end{array}$ & $\begin{array}{l}\text { CSF/CSF-1R pathway (GW2580, a } \\
\text { selective CSF1R kinase inhibitor) } \\
\text { or using 9-hydroxycanthin-6-one, } \\
\text { deoxyschizandrin). }\end{array}$ \\
\hline & $\begin{array}{l}\text { TAMs promote metastasis } \\
\text { dissemination thanks to the } \\
\text { secretion of CCL18 and matrix } \\
\text { support and growth factors (EGF) } \\
\text { within EOC spheroids floating in } \\
\text { the peritoneal fluid bound } \\
\text { together by integrins and ICAM-1 } \\
\text { via CD } 11 \mathrm{~b} / \mathrm{c} \text { binding. }\end{array}$ & \\
\hline & & $\begin{array}{l}\text { Re-activation of phagocytosis } \\
\text { inhibiting CD47 (EOC cells "don't } \\
\text { eat me signal" that binds TAMs' } \\
\operatorname{SIRP} \alpha \text { ). }\end{array}$ \\
\hline
\end{tabular}




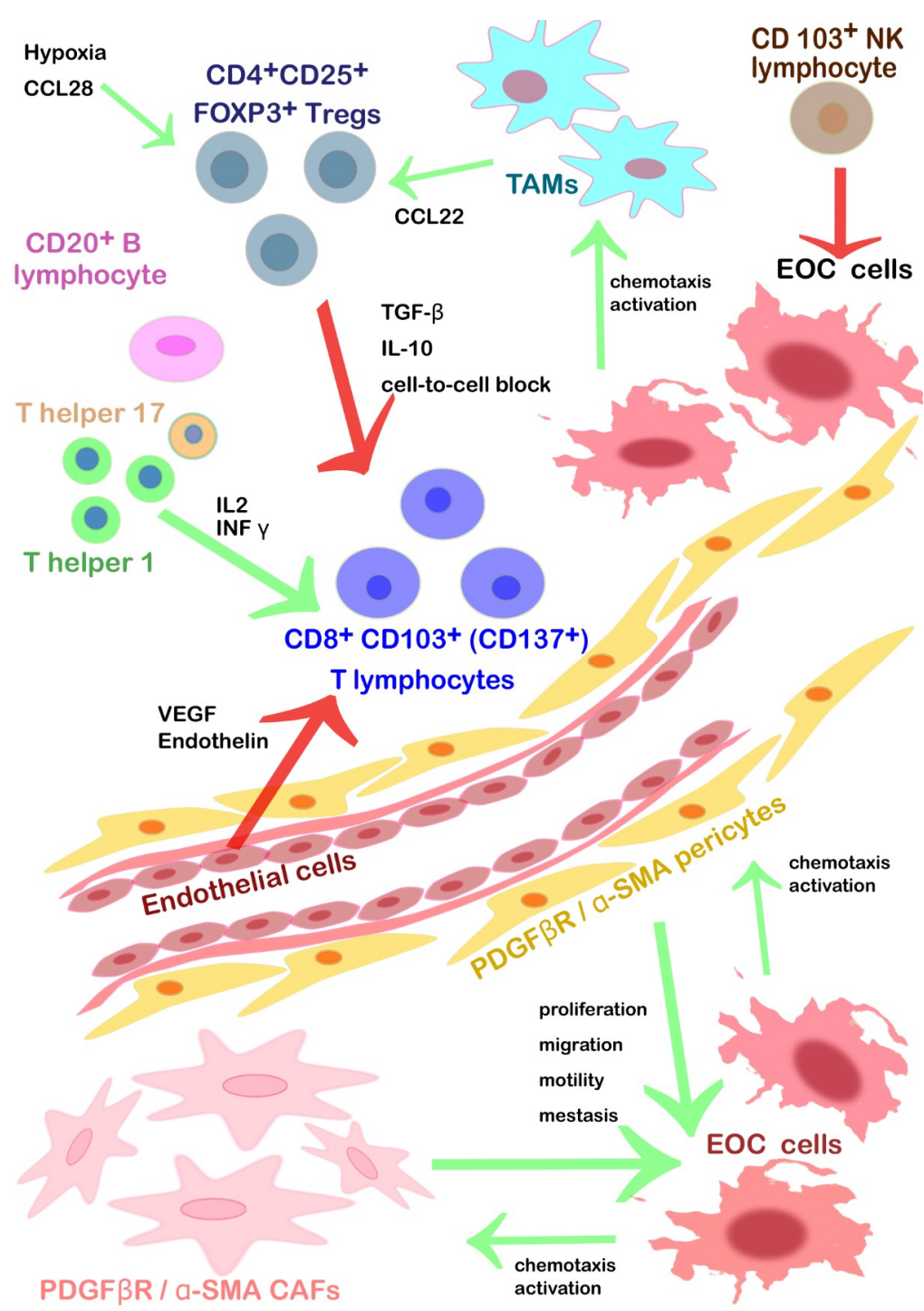

Figure 2. The main cell types that populate the EOC's TME: overall functions and cross-talks. Within EOC's tumoral islets, the stroma holds a variety of cell types, such as CAFs and $\alpha$-SMA+ pericytes. CAFs are recruited by PDGF $\beta$ and they promote EOC cells' motility, overgrowth, neo-angiogenesis, and invasion. $\alpha$-SMA+ pericytes are recruited by the PDGF $\beta$ and they reduce EOC cell-to-cell adhesion without affecting angiogenesis significantly unless providing guide-sheets for endothelial cells during neo-angiogenesis. Their rate and genetic signature correlate with proliferation, migration and cell motility of EOC. CAFs, $\alpha$-SMA+ pericytes and EOC cells communicate via a mutual cross-talk that creates a vicious cycle towards cancer progression. TILs include CD103 ${ }^{+} \mathrm{NK}$ lymphocytes, T helper 1 lymphocyte, $\mathrm{T}$ helper 17 lymphocytes, $\mathrm{CD} 8^{+} \mathrm{CD} 103^{+}\left(\mathrm{CD} 137^{+}\right)$lymphocytes. Monocytes from the bloodstream are chemoattracted by cancer cells and become resident TAMs, activated by IL10, IL6, TGF $\beta$, PUFAs and they play a key role in the EOC's biology (see Figure 1). Among TILs, there are $\mathrm{CD}_{103}{ }^{+} \mathrm{NK}$ lymphocytes that kill EOC cells expressing NKG2DLs. CD8 ${ }^{+} \mathrm{CD}_{103}{ }^{+}$(also CD137 ${ }^{+}$in most cases) cytotoxic $\mathrm{T}$ lymphocytes need to be activated by $\mathrm{T}$ helper lymphocytes (type 1 or 17) under the trigger of INF $\gamma$ and IL-2 to chase after cancer cells and to attack them as effector T cells. Resident $\mathrm{CD} 20^{+} \mathrm{B}$ cells cohabitate with effector T cells and they probably help them as APCs preventing their anergy. The diapedesis of this TILs is inhibited by endothelin and VEGF mainly from the endothelium. Among TILs, there are also $\mathrm{CD} 4{ }^{+} \mathrm{CD} 25^{+} \mathrm{FOXP}^{+} \mathrm{T}_{\text {regs }}$ that are activated by CCL28 under hypoxia condition and in the presence of $\mathrm{B} 7 \mathrm{H} 4^{+}$TAMs. They inhibit the cytotoxic functions of $\mathrm{T}$ cells effectors releasing inhibitory cytokines (TGF- $\beta$ and IL-10) or via a direct cell-to-cell block. The green arrows stand for positive stimuli, whereas the red ones represent an inhibition towards the pointed target. 


\section{Endometrial Cancer}

Endometrial cancer (EC) covers the main percentage of gynecological malignancies in Western countries. Its worldwide incidence accounts for 142000 cases per year with a life-long risk for the diagnosis of $1.71 \%[72,73]$. This cancer affects mainly post-menopause women since the median age at the diagnosis is 63 with an incidence peak in the next decade. Thanks to the early and frequent clinical presentation with abnormal vaginal bleeding, the diagnosis comes usually at initial stages with a good prognosis. Even considering patients with any stage of the disease, they will have a 5-year OS of about $80 \%$ [72,73].

EC mostly belongs to type I (80-90\%), which is estrogen-dependent and characterized by endometroid histology, early presentation at diagnosis, excellent prognosis, molecular signature, involving mutations of Phosphatase and Tensin homolog (PTEN), KRAS, Catenin Beta 1 (CTNNB1) and phosphoinositide 3 kinase (PI3K), the mismatch repair protein MutL Homolog 1 (MLH1) promoter hypermethylation and autotaxin hyperexpression [73,74]. Type II refers to a rare histological diagnosis (10-20\%), namely: serous, clear cell, undifferentiated carcinomas, carcinosarcoma/malignant mixed Müllerian tumor. They are known to recur even at early stages with a lower OS. Even though TP53 mutation is typical of serous EC, it could be identified in $\frac{1}{4}$ of endometrioid cancers, introducing some criticisms in the classical EC dichotomy. Therefore, the Cancer Genome Atlas (TCGA) Research Network describes four molecular types among endometrial tumors: 1. DNA POLymerase Epsilon (POLE) hypermutated tumors; 2 . tumors with microsatellite instability; 3 . tumors with a high rate of copy-number mutations, mainly involving TP53; 4 . tumors without any of the features listed above. There is also a hereditary EC, typically observed in association with hereditary non-polyposis colon cancer (HNPCC, Lynch syndrome) [73].

The pivotal treatment for EC is total hysterectomy with salpingo-oophorectomy, lymph node dissection or sentinel lymph node biopsy in selected cases, eventually followed by adjuvant radiotherapy according to the risk assessment. Only in advanced stages and special histotypes, such as serous ones, the adjuvant chemotherapy is considered [72,73].

Few studies have been conducted about the endometrial stroma focusing mostly on endometrioid ECs. Leukocytes, especially TAMs, as well as fibroblasts and myofibroblasts, compose the cell population under study that plays a crucial role in the malignant progression of hyperplasia leading to the hormonal sensitive EC [5,7,75-78].

\section{Mesenchymal Cells and their Autocrine and Paracrine Role in the Development of EC}

A recent study isolated and cultivated human endometrial stromal cells after removing all the leukocytes with an anti-CD45: the pillar population is represented by fibroblasts, which are typically positive for CD90, collagen 1 and 5B5. In the presence of PDGF, they can differentiate into myofibroblasts acquiring $\alpha$ SMA positivity. The remaining stroma hosts vascular smooth muscle cells, endothelial cells (CD31) and leukocytes [77].

Novel sensitive markers for endometrial stroma are CD10 or common acute lymphoblastic leukemia antigen and CD225 also named interferon-inducible transmembrane protein 1 . They could be useful during the pathological staging assessment, especially in case of troubling diagnosis of myometrium invasion. CD225 is more sensitive $(71.4 \%)$ and specific $(100 \%)$ than CD10 in detecting the stromal walls at the endometrial-myometrial junction in endometroid EC [78]. Notably, CD225 is more than a simple marker, because it plays a key role in mediating the antiproliferative and growth-inhibitory effects of INF $\gamma$. Since endometrial glands and myometrium lack of CD225, its absence at the correspondent staining indicates that the tumoral cells took the place of stromal ones and passed through the junction between endometrium and myometrium [78].

The crucial role of the stroma was recently observed through the effects of the mesenchymal deletion of ER $\alpha$ in a mouse model after bilateral oophorectomy. The treatment with exogenous $17 \beta$-estradiol (E2) leads to lower values of Ki67 among epithelial cells when the stroma is ER $\alpha$ deficient. It is known that the E2 pathway activates the ER $\alpha$ of mesenchymal cells leading to the release of growth factors, IGF1 or Tumor Growth Factor (TGF) and cell-cycle-related proteins, such as mitotic 
arrest deficient 2 like 1 (MAD2L1), Cyclin-Dependent Kinase Inhibitor 1A (CDKN1A) and CCAAT enhancer binding protein beta (CEBP $\beta)$ [7]. Thence, in the ESR1 deletion study, the E2-induced cascade of IGF1, MAD2L1, CDKN1A, and CEBP $\beta$ was attenuated [7]. In other words, stromal ER $\alpha$ mediates the E2 proliferative stimuli to the adjacent endometrium promoting the paracrine secretion of mesenchymal cells, as mentioned above [7]. Furthermore, IGF1 is the leading growth factor in the malignant progression from Endometrial Hyperplasia EH (EH) to EC in most of the cases, since the $80-90 \%$ of EC is estrogen-dependent [7,72]. The juxtacrine action of stromal cells can also influence the Progesterone Receptor (PR) expression of the neighboring epithelial cells: in case of ESR1 deletion, even during E2 therapy after ovariectomy in mouse, the endometrium had a PR loss [7]. In conclusion, the researchers evidenced the crucial relevance of the stromal ER $\alpha$ in mediating the full potential of the estrogenic proliferative trigger on the endometrial lining and determining its proper PR expression [7].

An interesting study evaluated the paracrine interaction between the peri-glandular stromal cells, identified with the expression CD10 and the epithelium in ECs, EH and controls [6]. The researchers started from the assumption that the mutation of CTNNB1, notoriously associated with endometrioid $\mathrm{EC}$ and $\mathrm{EH}$, results in abnormal expression of $\beta$-catenin. Its pathway is influenced by the hormonal milieu of endometrium since the $\beta$-catenin/E-cadherin rate is higher in the post-menopausal age than in pre-menopausal one. Moreover, it increases progressively through the multi-step progression from HE to EC [6]. Conversely, the expression of ER and PR within the stroma tend to decrease in the carcinogenesis process partly due to the influence of the disruptor $\beta$-catenin/E-cadherin. Notably, $\beta$-catenin and E-cadherin determine the regular architecture of endometrium, assuring the necessary cell-to-cell adhesion to the epithelium. The contemporary loss of E-cadherin and the up-regulation of $\beta$-catenin promote the epithelial-mesenchymal transition (EMT) in many types of cancers, including EC [6]. Stromal cells orchestrate the differentiation and the proliferation of the near epithelium components of the uterus, also managing the interaction between the $\beta$-catenin and the hormonal paracrine stimuli. Interestingly, the expression of many markers such as $\beta$-catenin and EMT-associated proteins (TWIST, SNAIL-SLUG) has the opposite behavior in epithelium and stroma. The peri-glandular stroma expression of $\beta$-catenin, SNAIL-SLUG, TWIST, ER and PR decreased significantly in EC compared to HE and in HE compared to controls [6]. Therefore, imbalanced homeostasis within the mesenchymal microenvironment leads the epithelium to lose the cell-to-cell adhesion, with the subsequent acquirement of the ability to escape from apoptosis, migrate and invade in response to ER activation [6]. Consequently, $\beta$-catenin and EMT-associated proteins expression levels were significantly higher in EC epithelium than EH and similarly in EH than controls. Conversely, E-cadherin decreased in EC more than EH and in EH compared to controls. This data could depict an interesting scenario where sex hormones, $\beta$-catenin, and EMT-associated proteins exert a cross-talk with the endometrium in the peritumoral mesenchyme, which contributes to the step-by-step development of EC from EH with atypia, which in turn comes from EH without atypia [6].

An overall view of the stromal cells that surround ECs is illustrated in Table 2 and in Figure 3

Table 2. Main cell types of the EC's TEM, their principal role in endometrial cancer (EC) pathogenesis and the possible translational value.

\begin{tabular}{ccc}
\hline Cell Type & Pathogenetic Role & Translational Possibilities \\
\hline $\begin{array}{c}\mathrm{ER} \alpha^{+} \text {fibroblasts and } \\
\text { myofibroblasts }\end{array}$ & $\begin{array}{c}\text { Juxtacrine and paracrine action on } \\
\text { endometrium with the secretion of } \\
\text { anti-apoptotic and proliferative } \\
\text { factors. }\end{array}$ & $\begin{array}{c}\text { Targeting stromal ER } \alpha \text { or the } \\
\text { further cascade-molecules: IGF1, } \\
\text { TGF and cell-cycle-related } \\
\text { proteins, such as MAD2L1, }\end{array}$ \\
& $\begin{array}{c}\text { Loss of } \beta \text {-catenin and EMT-associated } \\
\text { proteins (TWIST, SNAIL-SLUG) in an } \\
\text { opposite subset of EC cells } \rightarrow \text { enable } \\
\text { the near cancer cells to migrate, } \\
\text { invade and to escape from apoptosis. }\end{array}$ & $\begin{array}{c}\text { CDKN1A, and CEBP } \beta \text {.Targeting } \\
\text { stromal ER } \alpha \text { might revert also the } \\
\text { multistep tumoral process since it } \\
\text { is influenced by estrogens. }\end{array}$ \\
& & \\
\hline
\end{tabular}


Table 2. Cont.

\begin{tabular}{ccc}
\hline Cell Type & Pathogenetic Role & Translational Possibilities \\
\hline CD163 $3^{+}$M2 TAMs & $\begin{array}{c}\text { Re-education toward an antitumor, } \\
\text { immunostimulatory function } \\
\text { (PCX); blocking monocytes } \\
\text { Promote angiogenesis, LVSI, lymph } \\
\text { node metastasis, tumor overgrowth. } \\
\text { migration to the TME; activate the } \\
\text { phagocytic activity of TAMs; } \\
\text { blockade of PD-L1 on TAMs } \\
\text { (avelumab, nivolumab } \\
\text { pembrolizumab). }\end{array}$ \\
\hline
\end{tabular}

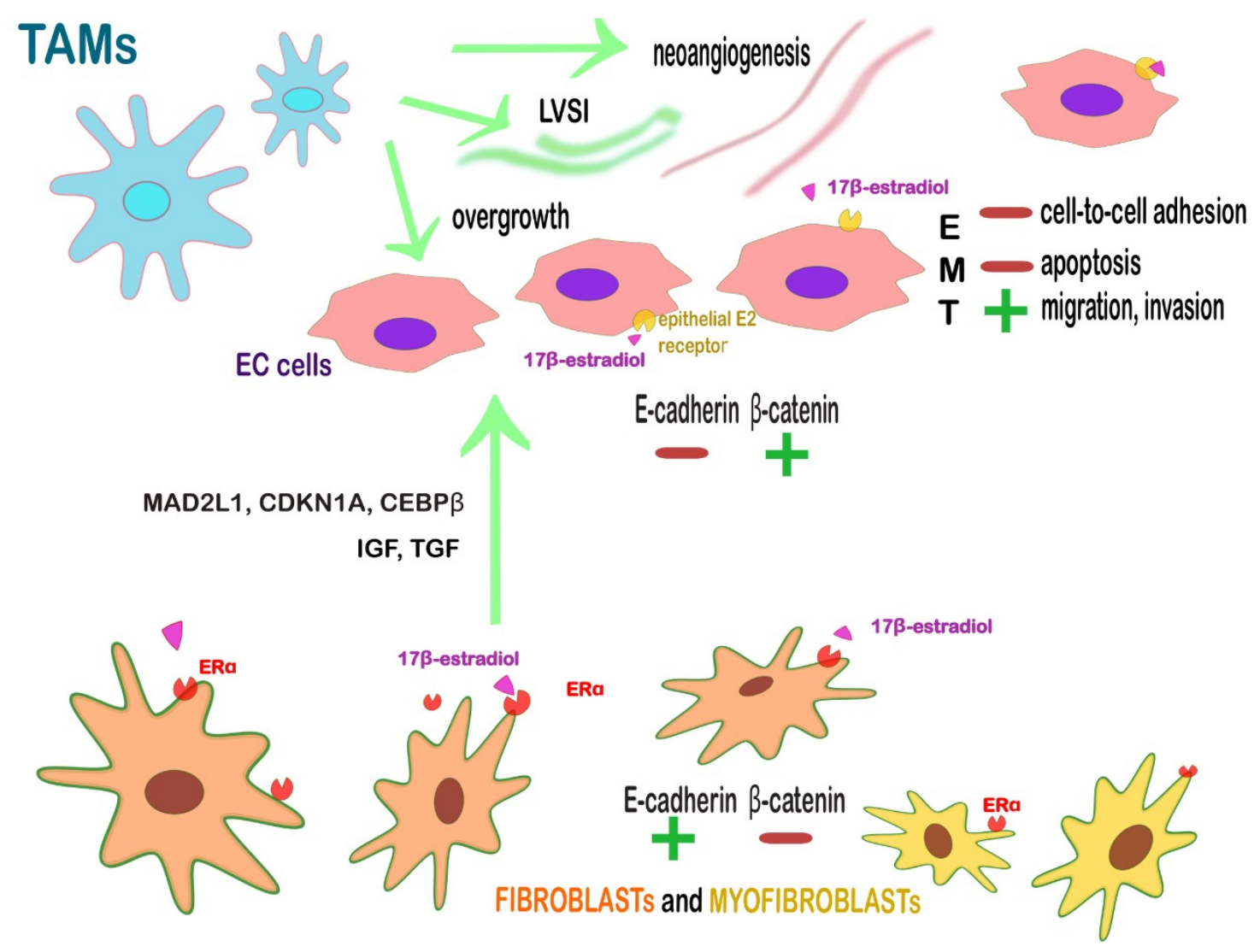

Figure 3. Crosstalk between endometrial cancer's (EC) cells and the surrounding stroma. The peritumoral stromal cells in EC are mainly composed by ER $\alpha+$ fibroblasts and myofibroblasts, TAMs and TILs. Fibroblasts and myofibroblasts, activated by the binding $17-\beta$-estradiol and its stromal receptor $\mathrm{ER} \alpha$, secret cell-cycle-related proteins (MAD2L1, CDKN1A, CEBP $\beta$ ) and growth factors (IGF, TGF). This juxtacrine and paracrine effect leads the epithelium to EMT losing the cell-to-cell adhesion and triggering the ability to escape from apoptosis, migrate and invade. The contemporary loss of E-cadherin and the up-regulation of $\beta$-catenin drive the EMT process leading to the alteration of the endometrial architecture and the subsequent multistep process towards EC. Fibroblasts and myofibroblasts act as sentinel and amplifier of estrogens on the neighboring endometrium. They are characterized by an opposite expression of E-cadherin/ $\beta$-catenin compared to the epithelium (represented as a green positive sign or as red negative one to indicate respectively increase and decrease) and they express $\alpha$ SMA marker. Other important actors within TEM are CD163 ${ }^{+}$M2 TAMs because they promote angiogenesis, LVSI, lymph node metastasis, and tumor overgrowth. The green arrows stand for positive stimuli. 


\section{Cervical Cancer}

Cervical cancer (CCx) represents the second most common malignancy among women all over the world and causes about 273200 deaths per year [79]. Its incidence is higher in Developing Countries and its roots lie in a gradual cancerous process from precancerous lesions, caused by unremitted high-risk HPV infections, sustained mainly by virus types 16 and 18 [79]. The multistep carcinomatous process could depend on the inefficient immune response within the cervical milieu, leading to the persistence of HPV-infected epithelial cells. Therefore, HPV infection, intraepithelial lesions, and their recurrence are more frequent in people with immunodeficiency and in women with a coexistent Chlamydia trachomatis infection [80]. HPV is characterized by two powerful oncoproteins, namely E6 and E7, able to downregulate the expression of TP53 and retinoblastoma protein (pRB) respectively leading to the cancer initiation and promotion $[9,79]$. Recent researches showed the critical role of tumor-associated NK cells as the first shield against microbes along the mucosal lining since they act as cytolytic lymphocytes and they also provide chemo-attractive molecules for other effector leukocytes. Consequently, this innate immune response correlates with a better prognosis in contrast with the EOCs [30,79]. Cancer-promoting effect of the high-risk HPVs works together with a high estrogen level within the local hormonal environment. Both experimental studies on mice and epidemiologic evaluations on a cohort of patients evidenced the crucial role of E2 and its stromal receptor ER $\alpha$ encoded by the gene ESR1 $[8,9]$. Notwithstanding the pillar role of CCx screening with Papanicolaou test and/or the HPV genotypisationsince their introduction in plummeting incidence and mortality, many women still escape from them. Since the leading cause of CCx is high-risk HPVs, a vaccine against them has now started a virtuous circle in reducing the percentage of HPV-affected young people and consequently in herd-immunity creation. Thence, the future challenge may be the HPV eradication thanks to efficient campaigns in favor of broad-spectrum vaccines [81].

\subsection{Inflammation, Pro-angiogenesis and Cancer-instructed Stromal Fibroblasts in CCx: Pathways and Translational Relevance}

$\mathrm{CCx}$ milieu can be considered as the final product of the effects of the persistent high-risk infection of HPV on epithelial cells that in turn instruct the surrounding stromal cells within the intercellular matrix. In precancerous and in early stages of cancer HPV oncoproteins modulate the immune response via the inhibition of pro-inflammatory molecular cascade in keratinocytes, mainly reducing the expression of CCL2 also referred as monocyte chemoattractant protein 1 (MCP1) and CCL20, also known as macrophage inflammatory protein-3 $\alpha$ (MIP3A) [10]. In the subsequent steps of cancer progression as in High-grade Squamous Intraepithelial Lesion (HSIL), cancer cells mold their stromal neighbors in chemo-attractors for dendritic cells and macrophages via the activation of CCL2/C-C motif Chemokine Receptor (CCR) [10].

Notably, higher stages of $C C x$ are associated with an increased expression of two innate immunity ligands, already named before in the sections related to EOC. These are MICA/B and ULBP1 and they rise at the same pace of cancer progression from Low-grade Squamous Intraepithelial Lesion (LSIL) to HSIL and invasive lesions [79]. Both these molecules bind NKG2D, so they are usually referred to as NKG2DLs (ligands). Even though NKG2D is typically found in NK cells, it characterizes also CD8 ${ }^{+}$ cytotoxic T cells and $\gamma \delta$-T cells. Screening, treatment, and follow-up of patients with this tumor may benefit from the rising value of NKG2DLs along the multi-step CCx evolution [79]. In other words, they can help in detecting pre-invasive lesions at high risk for cancer progression but they can also predict the kind of immune cells recruitment within the tumor-associated stroma. Since high levels of NKG2DLs reflect increased immune system activity against tumoral cells, recent research showed a strong positive correlation of PFS and OS with MICA and/or ULBP1 [79]. Notably, these findings do not match with the EOC's ones that identified MICA/B and ULBP2 as poor prognostic factors in EOC [30]. This controversial NKG2DLs' prognostic effect can be explained by specific cross-talks among different TEMs, such as cervical and ovarian ones, justifying opposite cellular reactions to similar starter actions. In details, CCx milieu is influenced by the paracrine activity of tumoral cells 
and its effect on all the stromal cellular populations, mainly represented by fibroblasts (vimentin ${ }^{+}$) and myofibroblasts $\left(\alpha \mathrm{SMA}^{+}\right)$. The cancer cells enable stromal ones to up-regulate CCL20 thanks to the paracrine trigger of the molecular cascade by the activation of the transcription factor CCAAT enhancer binding protein beta (C/EBP $\beta)$ and to the release of IL6 [10]. The latter has a wide range of functions: firstly, it acts as a chronic pro-inflammatory/pro-tumoral agent via the chemoattraction of Th17; secondly, it can be considered a disruptor of APCs helping cancer cells in immunity escape and a cancer promoter thanks to the induction of matrix metalloproteinase 9 (MMP-9) [10].

Therefore, higher rates of CCL20 call for its receptor CCR6 located on the CD4 ${ }^{+} / \mathrm{IL} 7^{+} / \mathrm{CCR} 6^{+}$ $\mathrm{T}$ lymphocytes, leading to the presence of Th17 TILs [10]. Their number is associated with invasive lesions and increases together with the progression of FIGO stage. Since the deletion of C/EBP $\beta$ and the inhibition of IL-6 impair significantly the migration properties of Th17 cells at more than $80 \%$ of their original activity, new therapies against this pro-tumorigenic subset may improve the therapies' options in case of advanced CCx [10]. Thence, paracrine agents like IL6, chemo-attractants like CCL20 or its activation pathway in the CCx-instructed fibroblasts may represent the next targets for personalized therapies in advanced CCx. Moreover, immunotherapy against Th17 can be translated also for CCx, as already done for EOC in the gynecological field.

The stromal milieu of CCx is rich of many other cytokines secreted after local epithelial-mesenchymal cross-talk. Interestingly, recent research discovered that the coculture of human CCX cells and autologous fibroblasts is associated to higher levels of CXCLs, mainly CXCL5 and CXCL1 and their receptor CXCR2 involved in a pro-angiogenic pathway [8]. Fibroblasts also face a massive ECM reorganization driven by HPV oncoproteins, E6 ed E7, that downregulate stroma expression of the fibronectin promoter, the powerful anti-angiogenic thrombospondins (THBS1, THBS2, and THBS3), tenascin C, about 15 genes encoding for collagen and cysteine-rich protein 61 . Stromal cells, which present a lack of their peculiar features, seem more like epithelial components after a process of mesenchymal-epithelial transition that may help HPV replication in reprogrammed cells [8]. Tumor-associated fibroblasts induce also the direct proliferation of keratinocytes, releasing a ligand of epidermal growth factor receptor (EGFR), namely heparin-binding EGF like growth factor (HBEGF), against which further studies may create monoclonal antibodies [8].

\subsection{Synergic Effects of Epithelial High-risk HPV and Stromal ER $\alpha$}

Persistent infection by high-risk HPVs is crucial but needs another ally to induce tumor development, namely, estrogens that increase during certain conditions like pregnancy or for iatrogenic reasons (oral contraceptives' assumption) [8]. Many epidemiological evaluations underline that woman affected by breast cancer in treatment with aromatase inhibitors were at reduced risk for CCx and its precursors thanks to lower E2 levels [9].

Since increased levels of E2 within the CCx stroma facilitate tumoral progression, a synergic effect between estrogens' pathway and HPV-oncoproteins has been discovered. Thence, a recent study on transgenic HPV-transgenic mice evidenced the expression of a peculiar chemokine/cytokine panel in the presence of exogenous treatment even in the case of epithelial knock-down for ER $\alpha$ [9]. Notably, the synergic effect of E6/E7 and E2 accounts for 40\% of up-regulated genes and 22\% of the down-regulated genes [8]. In details, the proliferative/pro-angiogenic/pro-inflammatory signature of the cancer microenvironment is sustained by HPV alone but also in concert with the E2 cascade, mostly mediated by the stromal ER $\alpha$ enhanced by the presence of tumor-associated fibroblasts [8,9]. Therefore, the stromal estrogen pathway feeds a vicious cycle led by the HPV oncoproteins, expressed by epithelium in a mutual paracrine cross-talk. Recent evidence revealed that E6/E7 keratinocytes treated with estrogens (E6/E7+E2) carry pro-inflammatory and tumor-promoting genome panels. Among the highly expressed genes, it has been remarkably described the role of chemokines belonging to the ELR+ CXC family that bind CXCR2, namely CXCL1, CXCL2, CXCL3, and CXCL5. Interestingly, they join the pathway of tumor initiation and angiogenesis within the precancerous lesions and the further malignant step. Other up-regulated molecules within the E6/E7+E2 stroma are IL1A and IL1B, 
fibroblast growth factor 9 (FGF9) and HBEGF, which can cooperate in providing an inflammatory milieu and anti-apoptotic escape for $\mathrm{HPV}^{+}$cells. According to Spurgeon et al. [8], the association between estrogen activity and HPV oncoproteins may orchestrate the mesenchymal concentration of pro-inflammatory and pro-angiogenic chemokine/cytokine, tumor-growth signals, cell-to-cell adhesion molecules, apoptosis escape, mesenchymal-to-epithelial transition and ECM plasticity in a transgenic mice model (E2+E6/E7) [8]. Since the epithelial receptor for E2 is not critical for CCx biological progression as the stromal one, blocking the mesenchymal expression of ER $\alpha$ in mice with $E 7^{+}$ keratinocytes determines the regression of cervical intraepithelial lesions [9]. Indeed, anti-estrogens down-regulate the amount of pro-inflammatory/pro-angiogenic molecules and growth factors (such as HBEGF) secreted by tumor-associated fibroblasts [8]. In the near future, the crucial role of stromal ER $\alpha$ in the cancerous promotion process of high-risk $\mathrm{HPV}^{+}$epithelium could become a potential target for therapeutic purposes.

An overall view of the main cell types of the CCx's TEM and their principal features are reported in Table 3 and in Figure 4 below.

Table 3. Main cell types of the CCx's TEM, their principal role in CCx pathogenesis and the possible translational value.

\begin{tabular}{|c|c|c|}
\hline Cell-Type & Pathogenetic Role & Translational Possibilities \\
\hline $\begin{array}{l}\text { Persistently high-risk HPV+ } \\
\text { keratinocytes }\end{array}$ & $\begin{array}{c}\text { Inhibition of inflammation in early } \\
\text { stages; progressive chemoattraction } \\
\text { for monocytes (MCP1 and MIP3A), } \\
\text { Th17 (CCL20, IL6) but also NK cells } \\
\text { in advanced stages }\end{array}$ & $\begin{array}{c}\text { Targeting EGFR, CCL2 (also } \\
\text { known as MCP1); CCL20, (also } \\
\text { known as MIP3A); IL6 }\end{array}$ \\
\hline $\begin{array}{l}\mathrm{ER} \alpha^{+} \text {fibroblasts and } \\
\text { myofibroblasts }\end{array}$ & $\begin{array}{l}\text { Mesenchymal-epithelial transition } \\
\text { Secretion of inflammatory } \\
\text { chemokines, anti-apoptotic, } \\
\text { pro-angiogenic factors and ECM } \\
\text { enzymes }\end{array}$ & $\begin{array}{l}\text { Targeting stromal ER } \alpha, \text { IL1A and } \\
\text { IL1B, FGF9, HBEGF, CXCR2 and } \\
\text { its ligands CXCLs (mainly CXCL5 } \\
\text { and CXCL1), MMP9. }\end{array}$ \\
\hline $\mathrm{CD}_{163^{+}}$M2 TAMs & $\begin{array}{l}\text { Promote angiogenesis, LVSI, lymph } \\
\text { node metastasis, tumor overgrowth }\end{array}$ & $\begin{array}{l}\text { Re-education toward an antitumor, } \\
\text { immunostimulatory function } \\
\text { (PCX); blocking monocytes } \\
\text { migration to the TME; activate the } \\
\text { phagocytic activity of TAMs; } \\
\text { blockade of PD-L1 on TAMs } \\
\text { (avelumab, nivolumab } \\
\text { pembrolizumab) }\end{array}$ \\
\hline $\mathrm{Th}_{17}$ lymphocytes & $\begin{array}{c}\text { Chronic } \\
\text { pro-inflammatory/pro-tumoral effect }\end{array}$ & $\begin{array}{l}\text { Targeting CCL20 and IL6; } \\
\text { re-education under IL2 stimuli }\end{array}$ \\
\hline NK lymphocytes & $\begin{array}{l}\text { Innate immune activity against } \\
\text { tumoral cells expressing MICA and } \\
\text { ULBP1 (NKG2DLs) }\end{array}$ & $\begin{array}{c}\text { Clonal autologous expansion; } \\
\text { vaccines against MICA and ULBP1 }\end{array}$ \\
\hline
\end{tabular}



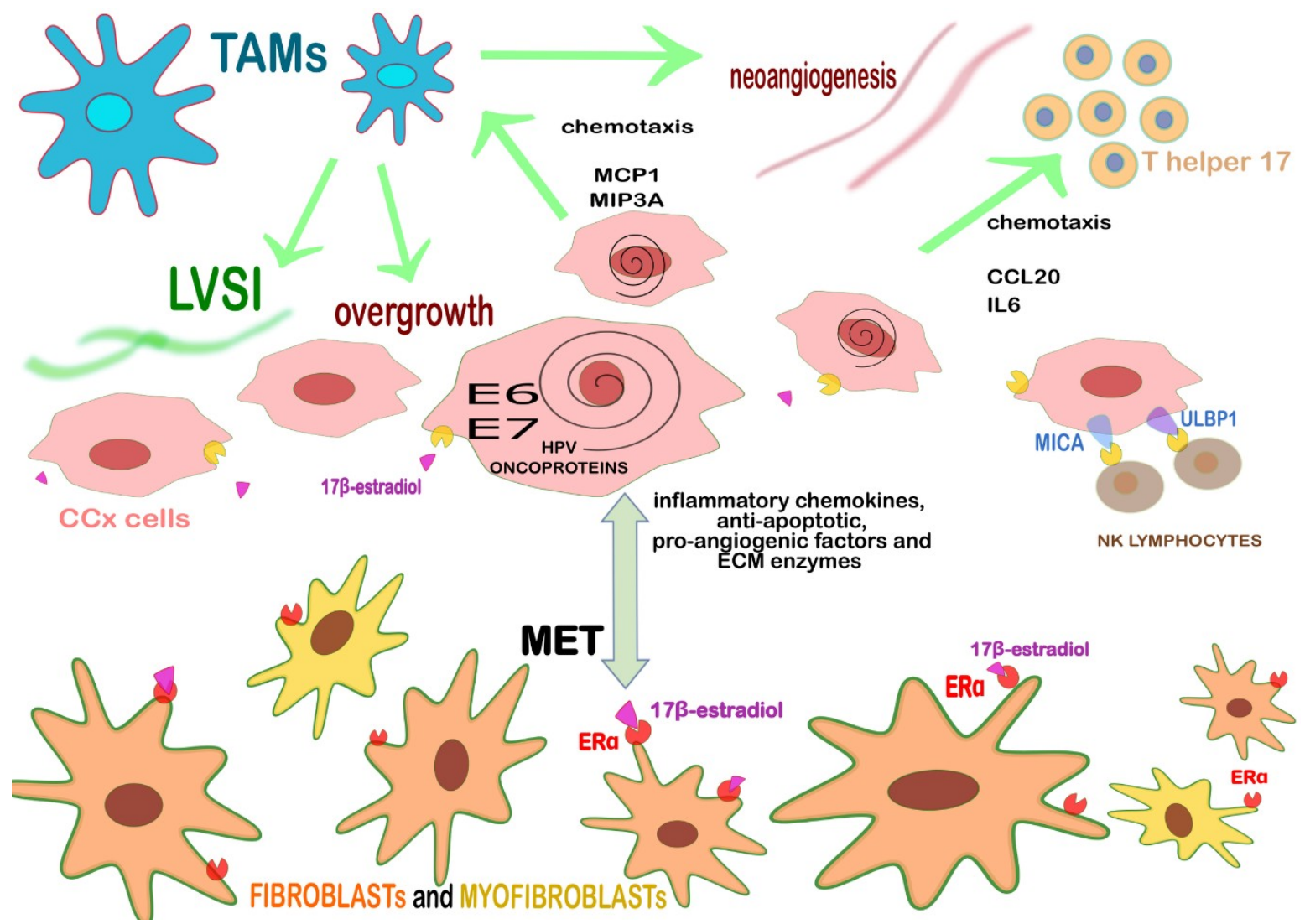

Figure 4. Crosstalk between CCx's cells and the surrounding stroma. The peritumoral stromal cells in CCx is mainly composed by ER $\alpha+$ fibroblasts and myofibroblasts, TAMs and TILs. Fibroblasts and myofibroblasts, activated by the binding $17-\beta$-estradiol and its stromal receptor ER $\alpha$ secrete inflammatory chemokines, anti-apoptotic, pro-angiogenic factors and ECM enzymes. They also go through the process of Mesenchymal-epithelial transition (MET). Persistently high-risk HPV+ keratinocytes that became CCx cells exert a chemoattraction for monocytes (MCP1 and MIP3A), Th17 lymphocytes (CCL20, IL6) but also NK cells in advanced stages. The proliferative/pro-angiogenic/pro-inflammatory signature of the TME is sustained by the oncoproteins (E6 and E7) of high-risk HPV but also in concert with the E2 cascade, mostly mediated by the stromal ER $\alpha$ enhanced by the presence of tumor-associated fibroblasts. MICA/B and ULBP1 expressed by CCx cells bind NKG2D, a receptor located on the NK lymphocyte's surface. Th17 lymphocytes play a role in sustain a chronic pro-inflammatory/pro-tumoral effect within TME, whereas NK lymphocytes increase the prognosis thanks to their cytotoxic activity against CCx cells. Other important actors within TEM are $\mathrm{CD}_{163^{+}} \mathrm{M} 2 \mathrm{TAMs}$ because they promote angiogenesis, LVSI, lymph node metastasis, and tumor overgrowth. The green arrows stand for positive stimuli.

\section{The Role of TAMs in Endometrial and Cervical Cancer and Their Translational Relevance in Gynecological Malignancies}

\subsection{TAMs in EC and CCX}

With respect to cervical and endometrial cancer, TAMs have been found to correlate with several unfavorable histological and clinical features [82]. Compared to benign tissues, endometrial and cervical carcinomas display higher $\mathrm{CD}^{+} 8^{+}$and $\mathrm{CD} 163^{+}$macrophages density [43-45]. Specifically, $\mathrm{CD}_{163}{ }^{+} \mathrm{M} 2-$ macrophages positively correlate with microvessel density, angiogenesis, lymphovascular space invasion, lymph node metastasis, as well as with higher FIGO stage, higher histological grade, increased expression of Ki-67 and p53 and a worse PFS [83-86]. In endometrial adenocarcinoma, TAMs inversely correlate with the expression of progesterone receptor [76] and with the enhanced sensitivity and addiction of endometrial cancer cells for estradiol [75]. In cervical cancer, a significant increase in 
VEGF-C expressing TAMs is correlated with tumor lympho-angiogenesis and lymphatic spread [86]. Moreover, in cervical adenocarcinoma patients, the presence of PD-L1 ${ }^{+}$TAMs and a lower M1/M2 ratio are associated with poor disease-specific survival $[87,88]$.

\subsection{Translational Significance of TAMs in Gynecological Malignancies}

The ongoing identification of the multifaceted function of TAMs is providing the opportunity for the development of novel therapies for gynecological cancers [82]. Furthermore, the affinity of TAMs to the peritoneal TME and the ascites offers future potential for targeted intraperitoneal treatments, in combination with classical chemotherapy drugs [82].

The main therapeutic strategies include the following:

(i) re-education of TAM function toward an antitumor, immunostimulatory function [40]. With this respect, the first-line treatment with Paclitaxel (PCX) has been proven useful to reprogram TAMs into a pro-inflammatory M1-profile via TLR4 signaling and this might contribute, at least in part, to the antitumor effect of PCX [89]. In HGSC, neferine (an alkaloid from lotus seed embryo) inhibits M2-macrophage polarization via mTOR/p70S6K pathway impairment, leading to an anti-angiogenetic effect [90]. Plant-derived products, such as 9-hydroxycanthin-6-one and deoxyschizandrin, have been found to inhibit M2-macrophages polarization in ovarian cancer [91,92]. Since the diverse function of macrophages are underpinned and sustained by specific metabolic signatures, targeting immuno-metabolism by the selective inhibition of the specific enzymes rather than ablation of general macrophage function is destined to represent a new attractive strategy to revert their function from M2 to M1 like [69,70];

(ii) blocking monocytes migration to the TME. Since EOC cells release the chemokine CCL2 to attract monocytes and convert them to TAMs within the TME [93], targeting CCL2 with selective antibodies might reduce monocyte infiltration and TAM differentiation. However, a clinical trial using an anti-CCL2 antibody, known as Carlumab or CNTO 888, has been completed (NCT01204996) with no significant results on tumor responses [45]. Bisphosphonates (such as clodronate, alendronic acid) are able to potentiate adoptive immunotherapy by depleting monocytes/macrophages in ovarian cancer [94]. Several inhibitors of the CSF/CSF-1R pathway, involved in the differentiation of monocytes into macrophages, both small molecules and antibodies, have been developed and are being studied in clinical trials. For example GW2580, a selective CSF1R kinase inhibitor, significantly reduces ascites fluid buildup, decreases the number of infiltrating TAMs and also repolarizes M2 macrophages within the tumor microenvironment to an M1-like phenotype [95];

(iii) activation of phagocytosis activity by macrophages. This strategy is being exploited thanks to the antigen CD47, expressed by ovarian cancer cells, that functions as a "don't eat me signal" through ligation of signal-regulatory protein alpha (SIRP $\alpha$ ) expressed on macrophages [96]. Targeting CD47 with antibodies induces a switch of TAMs polarization toward the anti-tumoral function by enhancing TAM mediated phagocytosis of cancer cells [96]. Clinical trials targeting CD47 are underway both as a single agent and in combination with anti-EGFR cetuximab [82];

(iv) blockade of PD-L1 on macrophages to increase activation of T cells. The robust expression of PD-L1 on TAMs likely contributes to T cell exhaustion and tumor-mediated immunosuppression. Several antibodies such as pembrolizumab, nivolumab and avelumab, targeting the PD-1/PD-L1 axis, are able to promote survival, activation and proliferation of $\mathrm{T}$ cells and are being tested clinically in patients with recurrent or refractory, platinum- and taxane-resistant ovarian cancer [97,98];

These novel strategies are partly showing their beneficial effects in ovarian cancer. However, more research is needed to achieve clinical efficacy and to evaluate the effects of existing and already used drugs, including trabectedin (an agent that intercalates with the DNA and causes DNA damage in tumor cells), bevacizumab (monoclonal antibody directed against VEGF) or olaparib, inhibitor of poly ADP-ribose polymerase (PARP), an enzyme involved in DNA repair. 


\section{Conclusions}

The main properties of malignant tumors' invasion, progression, and subsequent dissemination rely on cancer cells and the reaction of TME to their action. Considering the most common gynecological malignancies, intense crosstalk between the tumor and the surrounding stroma orchestrates the cancer behavior even in the gynecological field.

The translational significance of the tumor-associated stromal cells should be considered in developing new target therapy against instructed CAFs and activated pericytes since they strongly influence the TME, especially in the EOC.

Recent studies on immunotherapy have developed drugs able to restore the anti-tumorigenic balance of TILs, mainly cytotoxic T cells, T-regs and TAMs.

Estrogens and their stromal receptor $(\mathrm{ER} \alpha)$ in EC and CCx orchestrate the dialogue between the cancer cells and the mesenchymal micro-environment offering interesting translational results.

The action of E2 is powered by persistent high-risk HPV cervical infection, even though screening and vaccine campaigns have been decreasing the HPV-incidence since their introduction in developed Countries.

Author Contributions: Conceptualization, G.C., G.R. and R.D.N.; writing—original draft preparation, R.D.N. and A.M.; drafting of Figure 1-A.M. and A.C.; drafting of Tables 1-3 and Figures 2-4-R.D.N.; writing-reviewing and editing-R.D.N., A.C., V.L., G.R., E.C. and G.C.

Funding: This research received no external funding.

Acknowledgments: The authors would like the University of Bari for the Discovery Tool available on its official website for the literature research.

Conflicts of Interest: The authors declare no conflict of interest.

\section{Abbreviations}

\begin{tabular}{ll} 
EOC & Epithelial ovarian cancer \\
BM-MSCs & Bone-Marrow-Derived Mesenchymal Stem Cells \\
AOCS & Australian Ovarian Cancer Study \\
TME & Tumor Micro-Environment \\
EMT & Epithelial-Mesenchymal Transition \\
ECM & Extra-Cellular Matrix \\
CCL & Chemokine, C-C motif, Ligand \\
Th17 & T-helper 17 \\
HPV & Human Papilloma Virus \\
$\alpha$-SMA & Alpha Smooth Muscle Actin \\
PDGF $\beta R$ & Platelet Derived Growth Factor Beta Receptor \\
CAFs & Cancer-Associated Fibroblasts \\
FAP & Fibroblast Activation Protein \\
MCAM/CD146 & Melanoma Cell Adhesion Molecule/ Cluster of Differentiation 146 \\
CD & Cluster of Differentiation \\
FGF/FGFR & Fibroblast Growth Factor/ Fibroblast Growth Factor Receptor \\
VCAN & VersiCAN gene \\
VEGF-A & Vascular Endothelial Growth Factor-A \\
CXCL & Chemokine C-X-C motif ligand \\
PFS & Progression Free Survival \\
OS & Overall Survival \\
LCA & Leukocyte Common Antigen \\
TILs & Tumor-Infiltrating Lymphocytes \\
Tregs & T-regulatory cells \\
NK & Natural Killer \\
HSGC & High Serous Grade Carcinoma \\
TRM & Tissue Resident Memory \\
HLA & \\
& Human Leucocyte Antigens \\
\hline &
\end{tabular}




\section{Abbreviations}

\begin{tabular}{|c|c|}
\hline IL & InterLeukin \\
\hline INF $\gamma$ & INterFeron $\gamma$ \\
\hline PD-L1 & PD- Ligand 1 \\
\hline CTLA & Cytotoxic T-Lymphocyte-Associated Protein 4 \\
\hline $\mathrm{MHC}$ & Major Histocompatibility Complex \\
\hline ТР53 & Tumor Protein 53 \\
\hline APCs & Antigen-Presenting-Cells \\
\hline FOXP3 & Fork Head Box 3 \\
\hline TGF- $\beta$ & Tumor Grow Factor $\beta$ \\
\hline TAMs & Tumor-Associated Macrophages \\
\hline VEGF & Vascular Endothelial Growth Factor \\
\hline TNF & Tumor Necrosis Factor \\
\hline PLC $\gamma$ & PhosphoLipase $C_{\gamma}$ \\
\hline JAK/STAT & JAnus Kinase/Signal Transducer and Activator of Transcription \\
\hline PI3K & PhosphoInositide 3 Kinase \\
\hline Tim-3 & T-cell immunoglobulin and mucin-domain-containing-3 \\
\hline $\mathrm{MIC} \mathrm{A} / \mathrm{B}$ & Major histocompatibility complex class I-related chains (MIC) A and B \\
\hline ULBPs & UL-16 binding proteins \\
\hline NKG2D & Natural killer group 2, member D \\
\hline EC & Endometrial Cancer \\
\hline PTEN & Phosphatase and Tensin homolog \\
\hline CTNNB1 & Catenin Beta 1 \\
\hline PIK3CA & Phosphatidylinositol 3-kinase \\
\hline MLH1 & MutL Homolog 1 \\
\hline POLE & DNA POLymerase Epsilon \\
\hline HNPCC & Hereditary Non-Polyposis Colon Cancer \\
\hline $\mathrm{ER} \alpha$ & Estrogen Receptor $\alpha$ \\
\hline ESR1 & (gene) EStrogen Receptor 1 \\
\hline E2 & $17 \beta$-estradiol \\
\hline IGF1 & Insulin-like Growth Factor 1 \\
\hline TGF & Tumor Growth Factor \\
\hline MAD2L1 & Mitotic Arrest Deficient 2 Like 1 \\
\hline CDKN1A & Cyclin-Dependent Kinase Inhibitor 1A \\
\hline $\mathrm{EH}$ & Endometrial Hyperplasia \\
\hline PR & Progesterone Receptor \\
\hline $\mathrm{CCx}$ & Cervical cancer \\
\hline $\mathrm{pRB}$ & Retinoblastoma protein \\
\hline MCP1 & Monocyte Chemoattractant Protein 1 \\
\hline MIP3A & Macrophage Inflammatory Protein- $3 \alpha$ \\
\hline HSIL & High-grade Squamous Intraepithelial Lesion \\
\hline CCR & C-C motif Chemokine Receptor \\
\hline LSIL & Low-grade Squamous Intraepithelial Lesion \\
\hline $\mathrm{C} / \mathrm{EBP} \beta$ & CCAAT Enhancer Binding Protein Beta \\
\hline MMP-9 & Matrix-Metalloproteinase \\
\hline FIGO & International Federation of Gynaecology and Obstetrics \\
\hline THBS & Thrombospondins \\
\hline EGFR & Epidermal growth factor receptor \\
\hline HBEGF & Heparin Binding EGF Like Growth Factor \\
\hline FGF9 & Fibroblast Growth Factor 9 \\
\hline PUFAs & Polyunsaturated Fatty Acids \\
\hline Evs & Extracellular Vesicles \\
\hline VEGFR & Vascular Endothelial Growth Factor Receptor \\
\hline EGF & Endothelial Growth Factor \\
\hline
\end{tabular}




\section{Abbreviations}

$\begin{array}{ll}\text { EGFR } & \text { Endothelial Growth Factor Receptor } \\ \text { PCX } & \text { Paclitaxel } \\ \text { TLR } & \text { Toll-Like Receptor } \\ \text { SIRP } \alpha & \text { Signal-Regulatory Protein Alpha } \\ \text { CSF-1 } & \text { Colony-Stimulating Factor 1 } \\ \text { CSF1-R } & \text { Colony-Stimulating Factor 1 Receptor } \\ \text { LVSI } & \text { LymphoVascular Space Invasion } \\ \text { MET } & \text { Mesenchymal-epithelial transition }\end{array}$

\section{References}

1. Klymenko, Y.; Nephew, K.P. Epigenetic crosstalk between the tumor microenvironment and ovarian cancer cells: A therapeutic road less traveled. Cancers 2018, 10, 295. [CrossRef] [PubMed]

2. Corvigno, S.; Wisman, G.B.; Mezheyeuski, A.; van der Zee, A.G.; Nijman, H.W.; Avall-Lundqvist, E.; Ostman, A.; Dahlstrand, H. Markers of fibroblast-rich tumor stroma and perivascular cells in serous ovarian cancer: Inter- and intra-patient heterogeneity and impact on survival. Oncotarget 2016, 7, 18573-18584. [CrossRef]

3. Sinha, D.; Chong, L.; George, J.; Schluter, H.; Monchgesang, S.; Mills, S.; Li, J.; Parish, C.; Bowtell, D.; Kaur, P.; et al. Pericytes promote malignant ovarian cancer progression in mice and predict poor prognosis in serous ovarian cancer patients. Clin. Cancer Res. 2016, 22, 1813-1824. [CrossRef] [PubMed]

4. Tothill, R.W.; Tinker, A.V.; George, J.; Brown, R.; Fox, S.B.; Lade, S.; Johnson, D.S.; Trivett, M.K.; Etemadmoghadam, D.; Locandro, B.; et al. Novel molecular subtypes of serous and endometrioid ovarian cancer linked to clinical outcome. Clin. Cancer Res. 2008, 14, 5198-5208. [CrossRef] [PubMed]

5. Gibson, D.A.; Simitsidellis, I.; Collins, F.; Saunders, P.T.K. Endometrial intracrinology: Oestrogens, androgens and endometrial disorders. Int. J. Mol. Sci. 2018, 19, 3276. [CrossRef]

6. Senol, S.; Sayar, I.; Ceyran, A.B.; Ibiloglu, I.; Akalin, I.; Firat, U.; Kosemetin, D.; Engin Zerk, P.; Aydin, A. Stromal clues in endometrial carcinoma: Loss of expression of beta-catenin, epithelial-mesenchymal transition regulators and estrogen-progesterone receptor. Int. J. Gynecol. Pathol. 2016, 35, 238-248. [CrossRef]

7. Winuthayanon, W.; Lierz, S.L.; Delarosa, K.C.; Sampels, S.R.; Donoghue, L.J.; Hewitt, S.C.; Korach, K.S. Juxtacrine activity of estrogen receptor alpha in uterine stromal cells is necessary for estrogen-induced epithelial cell proliferation. Sci. Rep. 2017, 7, 8377. [CrossRef]

8. Spurgeon, M.E.; den Boon, J.A.; Horswill, M.; Barthakur, S.; Forouzan, O.; Rader, J.S.; Beebe, D.J.; Roopra, A.; Ahlquist, P.; Lambert, P.F. Human papillomavirus oncogenes reprogram the cervical cancer microenvironment independently of and synergistically with estrogen. Proc. Natl. Acad. Sci. USA 2017, 114, E9076-E9085. [CrossRef]

9. Son, J.; Park, Y.; Chung, S.H. Epithelial oestrogen receptor alpha is dispensable for the development of oestrogen-induced cervical neoplastic diseases. J. Pathol. 2018, 245, 147-152. [CrossRef]

10. Walch-Ruckheim, B.; Mavrova, R.; Henning, M.; Vicinus, B.; Kim, Y.J.; Bohle, R.M.; Juhasz-Boss, I.; Solomayer, E.F.; Smola, S. Stromal fibroblasts induce ccl20 through il6/c/ebpbeta to support the recruitment of th17 cells during cervical cancer progression. Cancer Res. 2015, 75, 5248-5259. [CrossRef]

11. Wang, X.; Zhu, Q.; Lin, Y.; Wu, L.; Wu, X.; Wang, K.; He, Q.; Xu, C.; Wan, X.; Wang, X. Crosstalk between tems and endothelial cells modulates angiogenesis and metastasis via igf1-igf1r signalling in epithelial ovarian cancer. Br. J. Cancer 2017, 117, 1371-1382. [CrossRef]

12. Hanahan, D.; Weinberg, R.A. Hallmarks of cancer: The next generation. Cell 2011, 144, 646-674. [CrossRef] [PubMed]

13. Pietras, K.; Ostman, A. Hallmarks of cancer: Interactions with the tumor stroma. Exp. Cell Res. 2010, 316, 1324-1331. [CrossRef]

14. Loizzi, V.; Del Vecchio, V.; Gargano, G.; De Liso, M.; Kardashi, A.; Naglieri, E.; Resta, L.; Cicinelli, E.; Cormio, G. Biological pathways involved in tumor angiogenesis and bevacizumab based anti-angiogenic therapy with special references to ovarian cancer. Int. J. Mol. Sci. 2017, 18, 1967. [CrossRef] [PubMed]

15. Levison, P.A.H.a.D.A. Review: Assessment of cell proliferation in histological material. J. Clin. Pathol. 1990, 43, 184-192. 
16. Strutz, F.; Zeisberg, M.; Renziehausen, A.; Raschke, B.; Becker, V.; Van Kooten, C.; Müller, G. Tgf- $\beta 1$ induces proliferation in human renal fibroblasts via induction of basic fibroblast growth factor (fgf-2). Kidney Int. 2001, 59, 579-592. [CrossRef] [PubMed]

17. Leinster, D.A.; Kulbe, H.; Everitt, G.; Thompson, R.; Perretti, M.; Gavins, F.N.; Cooper, D.; Gould, D.; Ennis, D.P.; Lockley, M.; et al. The peritoneal tumour microenvironment of high-grade serous ovarian cancer. J. Pathol. 2012, 227, 136-145. [CrossRef]

18. Marech, I.; Leporini, C.; Ammendola, M.; Porcelli, M.; Gadaleta, C.D.; Russo, E.; De Sarro, G.; Ranieri, G. Classical and non-classical proangiogenic factors as a target of antiangiogenic therapy in tumor microenvironment. Cancer Lett. 2016, 380, 216-226. [CrossRef]

19. Zhang, L.; Conejo-Garcia, J.R.; Katsaros, D.; Gimotty, P.A.; Massobrio, M.; Regnani, G.; Makrigiannakis, A.; Gray, H.; Schlienger, K.; Liebman, M.N.; et al. Intratumoral t cells, recurrence and survival in epithelial ovarian cancer. New Engl. J. Med. 2003, 348, 203-213. [CrossRef]

20. Santoiemma, P.P.; Powell, D.J., Jr. Tumor infiltrating lymphocytes in ovarian cancer. Cancer Biol. Ther. 2015, 16, 807-820. [CrossRef]

21. Schreiber, R.D.; Old, L.J.; Smyth, M.J. Cancer immunoediting: Integrating immunity's roles in cancer suppression and promotion. Science 2011, 331, 1565-1570. [CrossRef]

22. Lagana, A.S.; Sofo, V.; Vitale, S.G.; Triolo, O. Epithelial ovarian cancer inherent resistance: May the pleiotropic interaction between reduced immunosurveillance and drug-resistant cells play a key role? Gynecol. Oncol. Rep. 2016, 18, 57-58. [CrossRef]

23. Webb, J.R.; Milne, K.; Watson, P.; Deleeuw, R.J.; Nelson, B.H. Tumor-infiltrating lymphocytes expressing the tissue resident memory marker cd103 are associated with increased survival in high-grade serous ovarian cancer. Clin. Cancer Res. 2014, 20, 434-444. [CrossRef]

24. Abiko, K.; Matsumura, N.; Hamanishi, J.; Horikawa, N.; Murakami, R.; Yamaguchi, K.; Yoshioka, Y.; Baba, T.; Konishi, I.; Mandai, M. Ifn-gamma from lymphocytes induces pd-11 expression and promotes progression of ovarian cancer. Br. J. Cancer 2015, 112, 1501-1509. [CrossRef]

25. Nielsen, J.S.; Nelson, B.H. Tumor-infiltrating $\mathrm{b}$ cells and $\mathrm{t}$ cells: Working together to promote patient survival. Oncoimmunology 2012, 1, 1623-1625. [CrossRef]

26. Ranieri, G. Biological basis of tumor angiogenesis and therapeutic intervention: Past, present and future. Int. J. Mol. Sci. 2018, 19, 1655. [CrossRef]

27. Aoki, Y.; Takakuwa, K.; Kodama, S.; Tanaka, K.; Takahashi, M.; Tokunaga, A.; Takahashi, T. Use of adoptive transfer of tumor-infiltrating lymphocytes alone or in combination with cisplatin-containing chemotherapy in patients with epithelial ovarian cancer. Cancer Res. 1991, 51, 1934-1939.

28. Duraiswamy, J.; Kaluza, K.M.; Freeman, G.J.; Coukos, G. Dual blockade of pd-1 and ctla-4 combined with tumor vaccine effectively restores t-cell rejection function in tumors. Cancer Res. 2013, 73, 3591-3603. [CrossRef]

29. Guo, Z.; Cheng, D.; Xia, Z.; Luan, M.; Wu, L.; Wang, G.; Zhang, S. Combined tim-3 blockade and cd137 activation affords the long-term protection in a murine model of ovarian cancer. J. Transl. Med. 2013, 11, 215. [CrossRef]

30. Li, K.; Mandai, M.; Hamanishi, J.; Matsumura, N.; Suzuki, A.; Yagi, H.; Yamaguchi, K.; Baba, T.; Fujii, S.; Konishi, I. Clinical significance of the nkg2d ligands, mica/b and ulbp2 in ovarian cancer: High expression of ulbp2 is an indicator of poor prognosis. Cancer Immunol. Immunother. 2009, 58, 641-652. [CrossRef]

31. Pollard, J.W. Trophic macrophages in development and disease. Nat. Rev. Immunol. 2009, 9, $259-270$. [CrossRef]

32. Mantovani, A.; Sozzani, S.; Locati, M.; Allavena, P.; Sica, A. Macrophage polarization: Tumor-associated macrophages as a paradigm for polarized m2 mononuclear phagocytes. Trends Immunol. 2002, 23, 549-555. [CrossRef]

33. Lewis, C.E.; Pollard, J.W. Distinct role of macrophages in different tumor microenvironments. Cancer Res. 2006, 66, 605-612. [CrossRef]

34. Qian, B.-Z.; Pollard, J.W. Macrophage diversity enhances tumor progression and metastasis. Cell 2010, 141, 39-51. [CrossRef]

35. Marech, I.; Ammendola, M.; Sacco, R.; Sammarco, G.; Zuccala, V.; Zizzo, N.; Leporini, C.; Luposella, M.; Patruno, R.; Filippelli, G.; et al. Tumour-associated macrophages correlate with microvascular bed extension in colorectal cancer patients. J. Cell Mol. Med. 2016, 20, 1373-1380. [CrossRef] 
36. Condeelis, J.; Pollard, J.W. Macrophages: Obligate partners for tumor cell migration, invasion and metastasis. Cell 2006, 124, 263-266. [CrossRef]

37. Aras, S.; Zaidi, M.R. Tameless traitors: Macrophages in cancer progression and metastasis. Br. J. Cancer 2017, 117, 1583-1591. [CrossRef]

38. Hagemann, T.; Wilson, J.; Burke, F.; Kulbe, H.; Li, N.F.; Pluddemann, A.; Charles, K.; Gordon, S.; Balkwill, F.R. Ovarian cancer cells polarize macrophages toward a tumor-associated phenotype. J. Immunol. 2006, 176, 5023-5032. [CrossRef]

39. Kawamura, K.; Komohara, Y.; Takaishi, K.; Katabuchi, H.; Takeya, M. Detection of m2 macrophages and colony-stimulating factor 1 expression in serous and mucinous ovarian epithelial tumors. Pathol. Int. 2009, 59, 300-305. [CrossRef]

40. Noy, R.; Pollard, J.W. Tumor-associated macrophages: From mechanisms to therapy. Immunity 2014, 41, 49-61. [CrossRef]

41. Reinartz, S.; Schumann, T.; Finkernagel, F.; Wortmann, A.; Jansen, J.M.; Meissner, W.; Krause, M.; Schwörer, A.-M.; Wagner, U.; Müller-Brüsselbach, S.; et al. Mixed-polarization phenotype of ascites-associated macrophages in human ovarian carcinoma: Correlation of cd163 expression, cytokine levels and early relapse. Int. J. Cancer 2013, 134, 32-42. [CrossRef]

42. Colvin, E.K. Tumor-associated macrophages contribute to tumor progression in ovarian cancer. Front. Oncol. 2014, 4, 137. [CrossRef]

43. Zhang, M.; He, Y.; Sun, X.; Li, Q.; Wang, W.; Zhao, A.; Di, W. A high m1/m2 ratio of tumor-associated macrophages is associated with extended survival in ovarian cancer patients. J. Ovarian Res. 2014, 7, 19. [CrossRef]

44. He, Y.-F.; Zhang, M.-Y.; Wu, X.; Sun, X.-J.; Xu, T.; He, Q.-Z.; Di, W. High muc2 expression in ovarian cancer is inversely associated with the $\mathrm{m} 1 / \mathrm{m} 2$ ratio of tumor-associated macrophages and patient survival time. PLoS ONE 2013, 8, e79769. [CrossRef]

45. Gupta, V.; Yull, F.; Khabele, D. Bipolar tumor-associated macrophages in ovarian cancer as targets for therapy. Cancers 2018, 10, 366. [CrossRef]

46. Mhawech-Fauceglia, P.; Wang, D.; Ali, L.; Lele, S.; Huba, M.A.; Liu, S.; Odunsi, K. Intraepithelial t cells and tumor-associated macrophages in ovarian cancer patients. Cancer Immun. 2013, 13, 1.

47. Yuan, X.; Zhang, J.; Li, D.; Mao, Y.; Mo, F.; Du, W.; Ma, X. Prognostic significance of tumor-associated macrophages in ovarian cancer: A meta-analysis. Gynecol. Oncol. 2017, 147, 181-187. [CrossRef]

48. No, J.H.; Moon, J.M.; Kim, K.; Kim, Y.-B. Prognostic significance of serum soluble cd163 level in patients with epithelial ovarian cancer. Gynecol. Obstet. Investig. 2013, 75, 263-267. [CrossRef]

49. Lan, C.; Huang, X.; Lin, S.; Huang, H.; Cai, Q.; Wan, T.; Lu, J.; Liu, J. Expression of m2-polarized macrophages is associated with poor prognosis for advanced epithelial ovarian cancer. Technol. Cancer Res. Treat. 2013, 12, 259-267. [CrossRef]

50. Lane, D.; Matte, I.; Rancourt, C.; Piché, A. Prognostic significance of il-6 and il-8 ascites levels in ovarian cancer patients. BMC Cancer 2011, 11. [CrossRef]

51. Scambia, G.; Testa, U.; Benedetti Panici, P.; Foti, E.; Martucci, R.; Gadducci, A.; Perillo, A.; Facchini, V.; Peschle, C.; Mancuso, S. Prognostic significance of interleukin 6 serum levels in patients with ovarian cancer. Br. J. Cancer 1995, 71, 354-356. [CrossRef]

52. Lo, C.-W.; Chen, M.-W.; Hsiao, M.; Wang, S.; Chen, C.-A.; Hsiao, S.-M.; Chang, J.-S.; Lai, T.-C.; Rose-John, S.; Kuo, M.-L.; et al. Il-6 trans-signaling in formation and progression of malignant ascites in ovarian cancer. Cancer Res. 2010, 71, 424-434. [CrossRef]

53. Yanaihara, N.; Anglesio, M.S.; Ochiai, K.; Hirata, Y.; Saito, M.; Nagata, C.; Iida, Y.; Takakura, S.; Yamada, K.; Tanaka, T.; et al. Cytokine gene expression signature in ovarian clear cell carcinoma. Int. J. Oncol. 2012, 41, 1094-1100. [CrossRef]

54. Finkernagel, F.; Reinartz, S.; Lieber, S.; Adhikary, T.; Wortmann, A.; Hoffmann, N.; Bieringer, T.; Nist, A.; Stiewe, T.; Jansen, J.M.; et al. The transcriptional signature of human ovarian carcinoma macrophages is associated with extracellular matrix reorganization. Oncotarget 2016, 7. [CrossRef]

55. Worzfeld, T.; Pogge von Strandmann, E.; Huber, M.; Adhikary, T.; Wagner, U.; Reinartz, S.; Müller, R. The unique molecular and cellular microenvironment of ovarian cancer. Front. Oncol. 2017, 7. [CrossRef] 
56. Le Page, C.; Marineau, A.; Bonza, P.K.; Rahimi, K.; Cyr, L.; Labouba, I.; Madore, J.; Delvoye, N.; Mes-Masson, A.-M.; Provencher, D.M.; et al. Btn3a2 expression in epithelial ovarian cancer is associated with higher tumor infiltrating $\mathrm{t}$ cells and a better prognosis. PLoS ONE 2012, 7, e38541. [CrossRef]

57. Pogge von Strandmann, E.; Reinartz, S.; Wager, U.; Müller, R. Tumor-host cell interactions in ovarian cancer: Pathways to therapy failure. Trends Cancer 2017, 3, 137-148. [CrossRef]

58. Klimp, A.H.; Hollema, H.; Kempinga, C.; van der Zee, A.G.; de Vries, E.G.; Daemen, T. Expression of cyclooxygenase-2 and inducible nitric oxide synthase in human ovarian tumors and tumor-associated macrophages. Cancer Res. 2001, 61, 7305-7309.

59. Wang, X.; Deavers, M.; Patenia, R.; Bassett, R.L.; Mueller, P.; Ma, Q.; Wang, E.; Freedman, R.S. Monocytes/macrophage and $\mathrm{t}$-cell infiltrates in peritoneum of patients with ovarian cancer or benign pelvic disease. J. Transl. Med. 2006, 4, 30. [CrossRef]

60. Lane, D.; Matte, I.; Laplante, C.; Garde-Granger, P.; Carignan, A.; Bessette, P.; Rancourt, C.; Piché, A. Ccl18 from ascites promotes ovarian cancer cell migration through proline-rich tyrosine kinase 2 signaling. Mol. Cancer 2016, 15, 58. [CrossRef]

61. Curiel, T.J.; Coukos, G.; Zou, L.; Alvarez, X.; Cheng, P.; Mottram, P.; Evdemon-Hogan, M.; Conejo-Garcia, J.R.; Zhang, L.; Burow, M.; et al. Specific recruitment of regulatory t cells in ovarian carcinoma fosters immune privilege and predicts reduced survival. Nature Med. 2004, 10, 942-949. [CrossRef]

62. Valls, A.F.; Shen, Y.; Schmid, T. A core of macrophages facilitates ovarian cancer metastases. Transl. Cancer Res. 2017, 6, S189-S196. [CrossRef]

63. Sica, G.L.; Choi, I.-H.; Zhu, G.; Tamada, K.; Wang, S.-D.; Tamura, H.; Chapoval, A.I.; Flies, D.B.; Bajorath, J.; Chen, L. B7-h4, a molecule of the b7 family, negatively regulates t cell immunity. Immunity 2003, 18, 849-861. [CrossRef]

64. Kryczek, I.; Wei, S.; Zhu, G.; Myers, L.; Mottram, P.; Cheng, P.; Chen, L.; Coukos, G.; Zou, W. Relationship between b7-h4, regulatory t cells and patient outcome in human ovarian carcinoma. Cancer Res. 2007, 67, 8900-8905. [CrossRef]

65. Gottlieb, C.E.; Mills, A.M.; Cross, J.V.; Ring, K.L. Tumor-associated macrophage expression of pd-11 in implants of high grade serous ovarian carcinoma: A comparison of matched primary and metastatic tumors. Gynecol. Oncol. 2017, 144, 607-612. [CrossRef]

66. Zhou, J.; Li, X.; Wu, X.; Zhang, T.; Zhu, Q.; Wang, X.; Wang, H.; Wang, K.; Lin, Y.; Wang, X. Exosomes released from tumor-associated macrophages transfer mirnas that induce a treg/th17 cell imbalance in epithelial ovarian cancer. Cancer Immunol. Res. 2018, 6, 1578-1592. [CrossRef]

67. Yin, M.; Li, X.; Tan, S.; Zhou, H.J.; Ji, W.; Bellone, S.; Xu, X.; Zhang, H.; Santin, A.D.; Lou, G.; et al. Tumor-associated macrophages drive spheroid formation during early transcoelomic metastasis of ovarian cancer. J. Clin. Investig. 2016, 126, 4157-4173. [CrossRef]

68. Yang, L.; Moss, T.; Mangala, L.S.; Marini, J.; Zhao, H.; Wahlig, S.; Armaiz-Pena, G.; Jiang, D.; Achreja, A.; Win, J.; et al. Metabolic shifts toward glutamine regulate tumor growth, invasion and bioenergetics in ovarian cancer. Mol. Syst. Biol. 2014, 10, 728. [CrossRef]

69. Palmieri, E.M.; Menga, A.; Martín-Pérez, R.; Quinto, A.; Riera-Domingo, C.; De Tullio, G.; Hooper, D.C.; Lamers, W.H.; Ghesquière, B.; McVicar, D.W.; et al. Pharmacologic or genetic targeting of glutamine synthetase skews macrophages toward an m1-like phenotype and inhibits tumor metastasis. Cell Rep. 2017, 20, 1654-1666. [CrossRef]

70. Mazzone, M.; Menga, A.; Castegna, A. Metabolism and tam functions-it takes two to tango. FEBS J. 2017, 285, 700-716. [CrossRef]

71. Castegna, A.; Menga, A. Glutamine synthetase: Localization dictates outcome. Genes 2018, 9, 108. [CrossRef]

72. Amant, F.; Moerman, P.; Neven, P.; Timmerman, D.; Van Limbergen, E.; Vergote, I. Endometrial cancer. Lancet 2005, 366, 491-505. [CrossRef]

73. Colombo, N.; Creutzberg, C.; Amant, F.; Bosse, T.; Gonzalez-Martin, A.; Ledermann, J.; Marth, C.; Nout, R.; Querleu, D.; Mirza, M.R.; et al. Esmo-esgo-estro consensus conference on endometrial cancer: Diagnosis, treatment and follow-up. Int. J. Gynecol. Cancer 2016, 26, 2-30. [CrossRef]

74. Mazzocca, A.; Schonauer, L.M.; De Nola, R.; Lippolis, A.; Marrano, T.; Loverro, M.; Sabba, C.; Di Naro, E. Autotaxin is a novel molecular identifier of type i endometrial cancer. Med. Oncol. 2018, 35, 157. [CrossRef] 
75. Ning, C.; Xie, B.; Zhang, L.; Li, C.; Shan, W.; Yang, B.; Luo, X.; Gu, C.; He, Q.; Jin, H.; et al. Infiltrating macrophages induce er $\alpha$ expression through an il17a-mediated epigenetic mechanism to sensitize endometrial cancer cells to estrogen. Cancer Res. 2016, 76, 1354-1366. [CrossRef]

76. Jiang, X.-F.; Tang, Q.-I.; Li, H.-G.; Shen, X.-M.; Luo, X.; Wang, X.-Y.; Lin, Z.-Q. Tumor-associated macrophages correlate with progesterone receptor loss in endometrial endometrioid adenocarcinoma. J. Obstet. Gynaecol. Res. 2012, 39, 855-863. [CrossRef]

77. Chan, R.W.; Schwab, K.E.; Gargett, C.E. Clonogenicity of human endometrial epithelial and stromal cells. Biol. Reprod. 2004, 70, 1738-1750. [CrossRef]

78. Busca, A.; Djordjevic, B.; Giassi, A.; Parra-Herran, C. Ifitm1 is superior to cd10 as a marker of endometrial stroma in the evaluation of myometrial invasion by endometrioid adenocarcinoma. Am. J. Clin. Pathol. 2016, 145, 486-496. [CrossRef]

79. Cho, H.; Chung, J.Y.; Kim, S.; Braunschweig, T.; Kang, T.H.; Kim, J.; Chung, E.J.; Hewitt, S.M.; Kim, J.H. $\mathrm{Mica} / \mathrm{b}$ and $\mathrm{ulbp} 1 \mathrm{nkg} 2 \mathrm{~d}$ ligands are independent predictors of good prognosis in cervical cancer. BMC Cancer 2014, 14, 957. [CrossRef]

80. Crosbie, E.J.; Einstein, M.H.; Franceschi, S.; Kitchener, H.C. Human papillomavirus and cervical cancer. Lancet 2013, 382, 889-899. [CrossRef]

81. Townsend, J.S.; Steele, C.B.; Hayes, N.; Bhatt, A.; Moore, A.R. Human papillomavirus vaccine as an anticancer vaccine: Collaborative efforts to promote human papillomavirus vaccine in the national comprehensive cancer control program. J. Womens Health (Larchmt) 2017, 26, 200-206. [CrossRef]

82. Krishnan, V.; Schaar, B.; Tallapragada, S.; Dorigo, O. Tumor associated macrophages in gynecologic cancers. Gynecol. Oncol. 2018, 149, 205-213. [CrossRef]

83. Weber, S.K.; Sauerwald, A.; Pölcher, M.; Braun, M.; Debald, M.; Serce, N.B.; Kuhn, W.; Brunagel-Walgenbach, G.; Rudlowski, C. Detection of lymphovascular invasion by d2-40 (podoplanin) immunoexpression in endometrial cancer. Int. J. Gynecol. Cancer 2012, 22, 1442-1448. [CrossRef]

84. Salvesen, H.B.; Akslen, L.A. Significance of tumour-associated macrophages, vascular endothelial growth factor and thrombospondin-1 expression for tumour angiogenesis and prognosis in endometrial carcinomas. Int. J. Cancer 1999, 84, 538-543. [CrossRef]

85. Soeda, S.; Nakamura, N.; Ozeki, T.; Nishiyama, H.; Hojo, H.; Yamada, H.; Abe, M.; Sato, A. Tumor-associated macrophages correlate with vascular space invasion and myometrial invasion in endometrial carcinoma. Gynecol. Oncol. 2008, 109, 122-128. [CrossRef]

86. Ding, H.; Cai, J.; Mao, M.; Fang, Y.; Huang, Z.; Jia, J.; Li, T.; Xu, L.; Wang, J.; Zhou, J.; et al. Tumor-associated macrophages induce lymphangiogenesis in cervical cancer via interaction with tumor cells. APMIS 2014, 122, 1059-1069. [CrossRef]

87. Petrillo, M.; Zannoni, G.F.; Martinelli, E.; Pedone Anchora, L.; Ferrandina, G.; Tropeano, G.; Fagotti, A.; Scambia, G. Polarisation of tumor-associated macrophages toward $\mathrm{m} 2$ phenotype correlates with poor response to chemoradiation and reduced survival in patients with locally advanced cervical cancer. PLoS ONE 2015, 10, e0136654. [CrossRef]

88. Heeren, A.M.; Punt, S.; Bleeker, M.C.G.; Gaarenstroom, K.N.; van der Velden, J.; Kenter, G.G.; de Gruijl, T.D.; Jordanova, E.S. Prognostic effect of different pd-11 expression patterns in squamous cell carcinoma and adenocarcinoma of the cervix. Mod. Pathol. 2016, 29, 753-763. [CrossRef]

89. Wanderley, C.W.; Colon, D.F.; Luiz, J.P.M.; Oliveira, F.F.; Viacava, P.R.; Leite, C.A.; Pereira, J.A.; Silva, C.M.; Silva, C.R.; Silva, R.L.; et al. Paclitaxel reduces tumor growth by reprogramming tumor-associated macrophages to an m1- profile in a tlr4-dependent manner. Cancer Res. 2018, 78, 5891-5900. [CrossRef]

90. Zhang, Q.; Li, Y.; Miao, C.; Wang, Y.; Xu, Y.; Dong, R.; Zhang, Z.; Griffin, B.B.; Yuan, C.; Yan, S.; et al. Anti-angiogenesis effect of neferine via regulating autophagy and polarization of tumor-associated macrophages in high-grade serous ovarian carcinoma. Cancer Lett. 2018, 432, 144-155. [CrossRef]

91. Jeong, M.; Kim, H.M.; Ahn, J.-H.; Lee, K.-T.; Jang, D.S.; Choi, J.-H. 9-hydroxycanthin-6-one isolated from stem bark of ailanthus altissima induces ovarian cancer cell apoptosis and inhibits the activation of tumor-associated macrophages. Chem. Biol. Interact. 2018, 280, 99-108. [CrossRef]

92. Lee, K.; Ahn, J.-H.; Lee, K.-T.; Jang, D.; Choi, J.-H. Deoxyschizandrin, isolated from schisandra berries, induces cell cycle arrest in ovarian cancer cells and inhibits the protumoural activation of tumour-associated macrophages. Nutrients 2018, 10,91. [CrossRef] 
93. Negus, R.P.; Stamp, G.W.; Relf, M.G.; Burke, F.; Malik, S.T.; Bernasconi, S.; Allavena, P.; Sozzani, S.; Mantovani, A.; Balkwill, F.R. The detection and localization of monocyte chemoattractant protein-1 (mcp-1) in human ovarian cancer. J. Clin. Investig. 1995, 95, 2391-2396. [CrossRef]

94. Parente-Pereira, A.C.; Shmeeda, H.; Whilding, L.M.; Zambirinis, C.P.; Foster, J.; van der Stegen, S.J.C.; Beatson, R.; Zabinski, T.; Brewig, N.; Sosabowski, J.K.; et al. Adoptive immunotherapy of epithelial ovarian cancer with $\mathrm{v} \gamma 9 \mathrm{v} \delta 2 \mathrm{t}$ cells, potentiated by liposomal alendronic acid. J. Immunol. 2014, 193, 5557-5566. [CrossRef]

95. Moughon, D.L.; He, H.; Schokrpur, S.; Jiang, Z.K.; Yaqoob, M.; David, J.; Lin, C.; Iruela-Arispe, M.L.; Dorigo, O.; Wu, L. Macrophage blockade using csf1r inhibitors reverses the vascular leakage underlying malignant ascites in late-stage epithelial ovarian cancer. Cancer Res. 2015, 75, 4742-4752. [CrossRef]

96. Murata, Y.; Kotani, T.; Ohnishi, H.; Matozaki, T. The cd47-sirp signalling system: Its physiological roles and therapeutic application. J. Biochem. 2014, 155, 335-344. [CrossRef]

97. Disis, M.L.; Patel, M.R.; Pant, S.; Hamilton, E.P.; Lockhart, A.C.; Kelly, K.; Beck, J.T.; Gordon, M.S.; Weiss, G.J.; Taylor, M.H.; et al. Avelumab (msb0010718c; anti-pd-11) in patients with recurrent/refractory ovarian cancer from the javelin solid tumor phase ib trial: Safety and clinical activity. J. Clin. Oncol. 2016, 34, 5533. [CrossRef]

98. Hamanishi, J.; Mandai, M.; Ikeda, T.; Minami, M.; Kawaguchi, A.; Murayama, T.; Kanai, M.; Mori, Y.; Matsumoto, S.; Chikuma, S.; et al. Safety and antitumor activity of anti-pd-1 antibody, nivolumab, in patients with platinum-resistant ovarian cancer. J. Clin. Oncol. 2015, 33, 4015-4022. [CrossRef]

(C) 2019 by the authors. Licensee MDPI, Basel, Switzerland. This article is an open access article distributed under the terms and conditions of the Creative Commons Attribution (CC BY) license (http://creativecommons.org/licenses/by/4.0/). 